\title{
Research on Blade-Casing Rub-Impact Mechanism by Experiment and Simulation in Aeroengines
}

\author{
Jie Hong $\mathbb{D},{ }^{1,2}$ Tianrang Li $\mathbb{D},{ }^{1}$ Zhichao Liang $\mathbb{D}^{3},{ }^{3}$ Dayi Zhang $\mathbb{D},{ }^{1}$ and Yanhong Ma $\mathbb{D}^{1,2}$ \\ ${ }^{1}$ School of Energy and Power Engineering, Beihang University, Beijing 100083, China \\ ${ }^{2}$ Collaborative Innovation Center of Advanced Aero-Engine, Beijing 100083, China \\ ${ }^{3}$ Science and Technology on Complex Aviation Systems Simulation Laboratory, Beijing 100076, China \\ Correspondence should be addressed to Yanhong Ma; mayanhong@buaa.edu.cn
}

Received 29 December 2018; Revised 15 March 2019; Accepted 28 March 2019; Published 22 April 2019

Academic Editor: Luca Landi

Copyright ( $) 2019$ Jie Hong et al. This is an open access article distributed under the Creative Commons Attribution License, which permits unrestricted use, distribution, and reproduction in any medium, provided the original work is properly cited.

\begin{abstract}
Aeroengines pursue high performance, and compressing blade-casing clearance has become one of the main ways to improve turbomachinery efficiency. Rub-impact faults occur frequently with clearance decreasing. A high-speed rotor-support-casing test rig was set up, and the mechanism tests of light and heavy rub-impact were carried out. A finite element model of the test rig was established, and the calculation results were in good agreement with the experimental results under both kinds of rub-impact conditions. Based on the actual blade-casing structure model, the effects of the major physical parameters including imbalance and material characteristics were investigated. During the rub-impact, the highest stress occurs at the blade tip first and then it is transmitted to the blade root. Deformation on the impact blade tip generates easily with decreased yield strength, and stress concentration at the blade tip occurs obviously with weaker stiffness. The agreement of the computation results with the experimental data indicates the method could be used to estimate rub-impact characteristics and is effective in design and analyses process.
\end{abstract}

\section{Introduction}

The clearance between the rotor and stator is supposed to be smaller in modern aeroengines to improve the efficiency and power output [1]. As a consequence, the rub-impact between the rotor and stator is more likely to occur, which may cause the economic loss, influence the safety of the engine, and even lead to catastrophic failures [2]. Hence, the evaluation of the rotating machines' condition and the investigation of the rub-impact are always hot topics in research fields.

During the past decades, significant research achievement has been obtained in the prediction and measurement of rub-impact phenomena. Muszynska [3], Ahmad [4], and Jacquet-Richardet et al. [5] made comprehensive reviews on this problem and gave a list of previous papers on the rubrelated vibration phenomena. Karpenko et al. [6], Feng and Zhang [7], Sinha [8], Batailly et al. [9], Villa et al. [10], and Legrand et al. [11] devoted to nonlinear dynamics of rubimpact by theory analysis and numerical simulation. Ma et al. [12], Sinha [13], Khanlo et al. [14], and Liao et al. [15] showed the methodologies to determine the bouncing and rolling contact loads of rub-impact between a flexible spinning shaft and an outer cylindrical ring. On experimental research, Pennacchi [16] presented an experimental study and a mathematical model to analyze the effects of rotor-to-stator rub on seals. Chu and Lu [17] installed an experimental setup to analyze nonlinear responses and bifurcation characteristics. Torkhani et al. [18] compared theoretical predictions with the experimental results under different rub-impact conditions including partial light, medium, and heavy rubs.

In recent years, new progress has been made in the study of rub-impact problems; however, insufficiencies can also be seen. Concerning the flexibility of the casing, Li et al. [19] deduced an improved rotating blade-casing rubbing model based on elastic compatibility conditions. Yang et al. [20, 21] conducted rubbing characteristics analysis in a dual-rotor system based on the Lankarani-Nikravesh model, but 
limited to fixed-point rubbing. Ma $[22,23]$ and Sun et al. [24] did some work on the establishment of accurate models. $\mathrm{Ma}$ and $\mathrm{Lu}$ [25] studied the influence of stagger angles of blades, rotational speeds, and casing stiffness on the rubbing-induced vibration responses, but lack of experimental verification. Concerning thermal effects on blades in rub-impact, Nyssen and Batailly [26] investigated the numerical modelling of thermal effects within the abradable layer during contact interactions and compared it with experimental data. In their work, a weak thermomechanical coupling was assumed, but only heat transfer by conduction was considered. On fault recognition and diagnosis, Chen [27-29] studied casing vibration characteristics both in simulation and experimental methods. Single-point, multipoint, partial, and complete-cycle rubbing were concerned. Impact signals were obtained from casing vibration accelerations. Wang et al. [30] did similar research in a dualrotor-blade-casing system. Influences of some variables on dynamic behaviors had been investigated, but the simulation results had not been verified by experiments.

Multiphysics, multiscale, and strong nonlinear are involved in rub-impact. There are still lots of work to be done on this problem. In this article, a simulation method based on the FEM (finite element method) software including mechanism of computation and analysis procedures was presented. A test rig considering the structural characteristics of the rotor-support-casing system was established to verify the validity of the simulation method. Then, a calculation on blade-casing rub-impact in the actual turbine of the aeroengine was conducted. Response characteristics and parameter influences were obtained. These calculation results are of great importance in optimization of the designed structures to obtain acceptable dynamic responses in rubimpact. This is also the engineering application value of this article.

\section{Theoretical Model of Rub-Impact}

2.1. Mechanical Model. In Figure 1 is shown the simplified model of rotor system, which is composed of shaft, disk, blades, bearings, supports, and casing. The elastically deformable blades may rub against the internal surface of the outer containment structure due to the imbalance excitation.

The dynamical equation of the rotor is shown as follows:

$$
\begin{aligned}
& {\left[\begin{array}{ccc}
\mathbf{M}_{\mathrm{r}} & & \\
& \mathbf{M}_{\mathrm{b}} & \\
& & \mathbf{M}_{\mathrm{c}}
\end{array}\right] \ddot{Z}+\left[\begin{array}{lll}
\mathbf{C}_{\mathrm{rr}} & \mathbf{C}_{\mathrm{rb}} & \\
\mathbf{C}_{\mathrm{br}} & \mathbf{C}_{\mathrm{bb}} & \\
& & \mathbf{C}_{\mathrm{cc}}
\end{array}\right] \dot{Z}+\left[\begin{array}{lll}
\mathbf{K}_{\mathrm{rr}} & \mathbf{K}_{\mathrm{rb}} & \\
\mathbf{K}_{\mathrm{br}} & \mathbf{K}_{\mathrm{bb}} & \\
& & \mathbf{K}_{\mathrm{cc}}
\end{array}\right] \mathbf{Z}} \\
& +\left[\begin{array}{lll}
\mathbf{B}_{\mathrm{r}}(t) & & \\
& \mathbf{B}_{\mathrm{b}}(t) & \\
& & \mathbf{B}_{\mathrm{c}}(t)
\end{array}\right] \mathbf{Z}=\mathbf{F}_{\mathrm{un}}+\mathbf{P}_{\mathrm{rub}}
\end{aligned}
$$

where $\mathbf{M}_{\mathrm{r}}, \mathbf{M}_{\mathrm{b}}$, and $\mathbf{M}_{\mathrm{c}}$ are the mass matrixes of the rotor, blades, and casing, respectively; $\mathbf{C}_{\mathrm{rr}}, \mathrm{C}_{\mathrm{bb}}, \mathrm{C}_{\mathrm{cc}}, \mathbf{C}_{\mathrm{rb}}, \mathbf{C}_{\mathrm{br}}$ and $\mathbf{K}_{\mathrm{rr}}, \mathbf{K}_{\mathrm{bb}}, \mathbf{K}_{\mathrm{cc}}, \mathbf{K}_{\mathrm{rb}}, \mathbf{K}_{\mathrm{br}}$ are the matrixes of damping and stiffness. $\mathbf{B}_{\mathrm{r}}(t), \mathbf{B}_{\mathrm{b}}(t)$, and $\mathbf{B}_{\mathrm{c}}(t)$ are the time-varying matrixes induced by contact: $\mathbf{B}_{\mathrm{r}}(t)$ is the additional stiffness of the rotor depended on the rotation speed; $\mathbf{B}_{\mathrm{b}}(t)$ is the additional stiffness caused by the contact between the blades and the casing which is related to the rotation speed and the deformation of blades; $\mathbf{B}_{\mathrm{c}}(t)$ is the additional stiffness of the casing caused by its deformation. $\mathbf{Z}$ is the displacement vector; $\mathbf{F}_{\text {un }}$ and $\mathbf{P}_{\text {rub }}$ denote the imbalance force and the rubimpact force. It is assumed that the support stiffness is large enough.

In equation (1), $\mathbf{M}, \mathbf{C}$, and $\mathbf{K}$ could be obtained by the finite element method, while $\mathbf{B}$ and $\mathbf{P}_{\text {rub }}$ are usually difficult to determine due to the combined effect of a number of factors, such as the motion status, deformation, material and structural characteristics. The rub-impact force $\mathbf{P}_{\text {rub }}$ includes the impact force $\mathbf{F}_{\mathrm{n}}$ and the friction force $\mathbf{F}_{\mathrm{f}}$, which could be described as follows based on Hertz contact theory.

$$
\mathbf{p}_{\text {rub }}=\left\{\begin{array}{c}
\mathbf{F}_{\mathrm{n}} \\
\mathbf{F}_{\mathrm{f}}
\end{array}\right\}=\left\{\begin{array}{c}
\left\{f\left(\Delta \mathrm{z}_{\mathrm{rub}}(t)\right)\right\} \\
\left\{\mu(v) F_{\mathrm{n}}\right\}
\end{array}\right\} .
$$

In equation (2), normal force $\mathbf{F}_{\mathrm{n}}$ which is determined by the clearance $\Delta z_{\text {rub }}$ at the contact point influences the rebounding motion of the rotor. Tangential force $\mathbf{F}_{\mathrm{f}}$ is determined by the friction between the rotor and stator.

2.2. Dynamic Contact. Some widely used approaches to describe the contact mechanics are the kinematic constraint method, distributed parameter method, Lagrange multiplier method, and penalty method. In this paper, the symmetric penalty method was implanted in the rotor dynamic analysis to consider the rub-impact. As shown in Figure 2, the geometric center of the rotor and casing are $\mathrm{O}_{r}$ and $\mathrm{O}_{c}$, respectively, while point $B$ of the blade and point $C$ of the casing are selected as a contact pair; the clearance $\Delta z_{\text {rub }}$ is equal to the distance between $\mathrm{B}$ and $\mathrm{C}$.

Once the clearance is determined, the normal force could be given as follows:

$$
\mathbf{F}_{\mathrm{n}}= \begin{cases}0, & \text { if } \Delta z_{\mathrm{rub}}>0, \\ \frac{-\Delta z_{\mathrm{rub}} f_{s i} k_{i} A_{i}^{2} \mathbf{n}_{i},}{V_{i}}, & \text { if } \Delta z_{\mathrm{rub}}<0,\end{cases}
$$

where $f_{s i}$ is the scale factor of contact stiffness, which has a significant influence on the calculation speed and stability of the algorithm; $k_{i}, A_{i}$, and $V_{i}$ are the bulk modulus, area, and volume of the element, respectively, while $\mathbf{n}_{i}$ is the outward normal unit vector at the contact point $\mathrm{B}\left(\xi_{\mathrm{B}}, \eta_{\mathrm{B}}\right)$, which can be calculated as follows:

$$
\mathbf{n}_{i}=\frac{\partial \mathbf{r} / \partial \xi\left(\xi_{\mathrm{B},} \eta_{\mathrm{B}}\right) \times \partial \mathbf{r} / \partial \eta\left(\xi_{\mathrm{B}} \eta_{\mathrm{B}}\right)}{\left|\partial \mathbf{r} / \partial \xi\left(\xi_{\mathrm{B}} \eta_{\mathrm{B}}\right) \times \partial \mathbf{r} / \partial \eta\left(\xi_{\mathrm{B}} \eta_{\mathrm{B}}\right)\right|}
$$

The friction force is calculated based on the Coulomb friction model. $\mathbf{F}_{\mathrm{y}}$ is the yield friction force; $\mathbf{F}^{*}$ is defined as the trial friction force: 


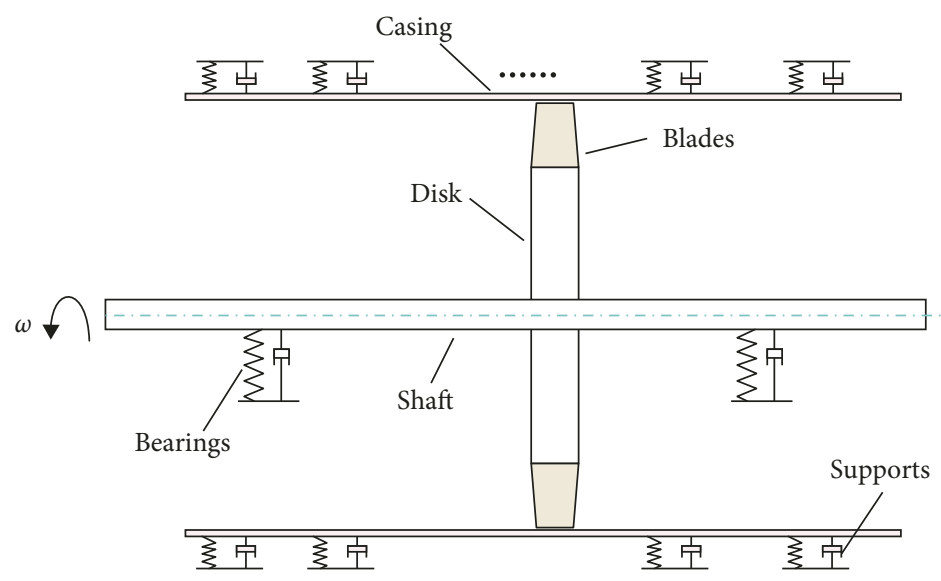

FIgURE 1: Simplified model of rotor system.

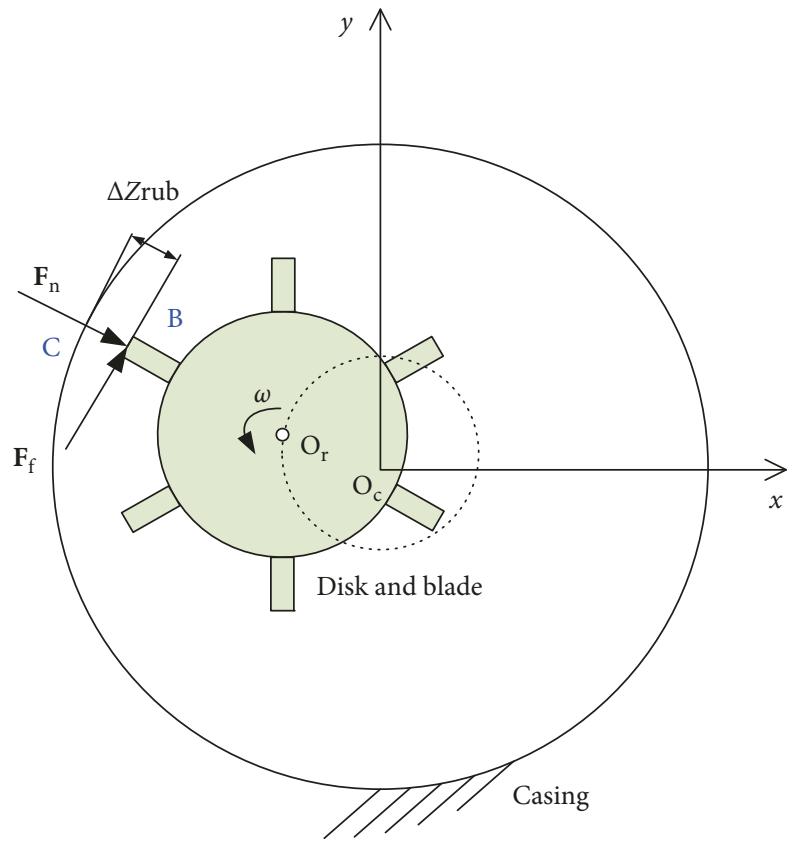

Figure 2: Model of a rotor rubbing against the casing.

$$
\begin{aligned}
& F_{\mathrm{y}}=v\left|\mathbf{F}_{\mathrm{n}}\right|, \\
& \mathbf{F}^{*}=\mathbf{F}_{\mathrm{f}}^{n}-\beta \Delta \mathbf{e},
\end{aligned}
$$

where $v$ is the friction coefficient, $\mathbf{F}_{\mathbf{n}}$ is the normal force, $\mathbf{F}_{\mathrm{f}}^{n}$ is the friction force at the moment $t_{n}, \beta$ is the contact stiffness, and $\Delta \mathbf{e}$ is the dynamic increment. The friction force is given as follows:

$$
\mathbf{F}_{\mathrm{f}}^{n+1}= \begin{cases}\mathbf{F}^{*}, & \text { if }\left|\mathbf{F}^{*}\right| \leq F_{\mathrm{y}}, \\ \frac{F_{\mathrm{y}} \cdot \mathbf{F}^{*}}{\left|\mathbf{F}^{*}\right|}, & \text { if }\left|\mathbf{F}^{*}\right|>F_{\mathrm{y}} .\end{cases}
$$

According to the equations (3) and (6), the following parameters will affect the results directly in numerical analysis, including the rotor/casing clearance $\Delta z_{\text {rub }}$, bulk modulus $k_{i}$, contact area $A_{i}$, and friction coefficient $\mu$.
Therefore, it is important to set the parameters with a suitable value in finite element analysis to get credible results.

\section{Rub-Impact Experiment and Mechanism Analysis}

In this section, the experiments were performed, including light and heavy rub-impact conditions, to observe the rubimpact phenomena and analyze the response characteristics.

\subsection{Experimental Setup}

3.1.1. Test Facility. A high-speed rotor test rig is shown in Figure 3(a), and it includes a foundation, motor, supports, rotor, lubricating system, and vibration amplitude measurement unit. The rotating speed of the motor was controlled by a computer system to keep a stable acceleration and deceleration. A flexible coupling which could tolerate the small misalignment between the rotor and the motor supports was used to connect the motor to the test rotor. A disk with six blades was installed on the rotor which was supported by two bearings. Each blade was simplified as a flat plane without complex geometrical configuration. The test point is shown in Figure 3(b), while the orbits of the rotor were measured by the displacement sensors located near the left rigid support. In order to simulate the different conditions of the rub-impact, a rubbing ring shown in Figure 3(c) with a tapered inner shell was designed that can move axially to change the initial clearance (from 0 to $0.5 \mathrm{~mm}$ ) between the blade and the casing. The casing was fixed to the foundation through steel beams (Figure 3(b)).

The length of the test rig is $4 \mathrm{~m}$, and the width is $1.5 \mathrm{~m}$. Key parameters of the rotor are listed in Table 1.

3.1.2. Finite Element Model. A finite element model was built as shown in Figure 4. The disk and blades were modelled by $3 \mathrm{D}$ brick elements, the shaft and the casing were modelled by $2 \mathrm{D}$ shell elements, and the supports were modelled by spring elements. The material parameters were 


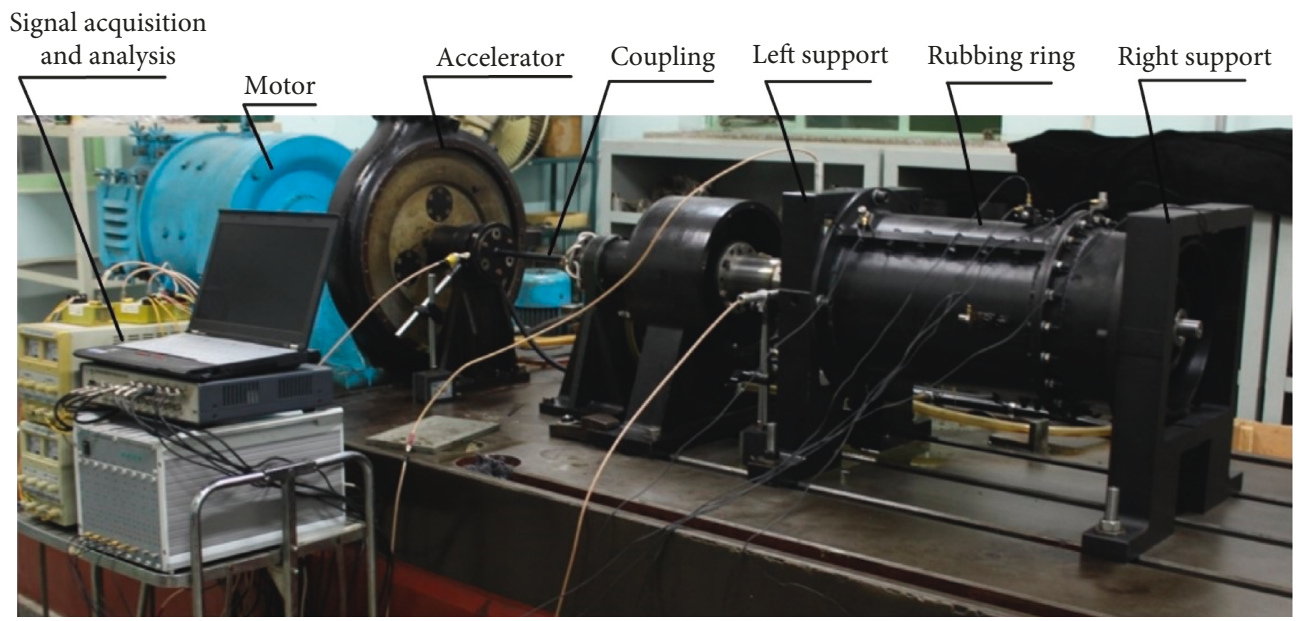

(a)

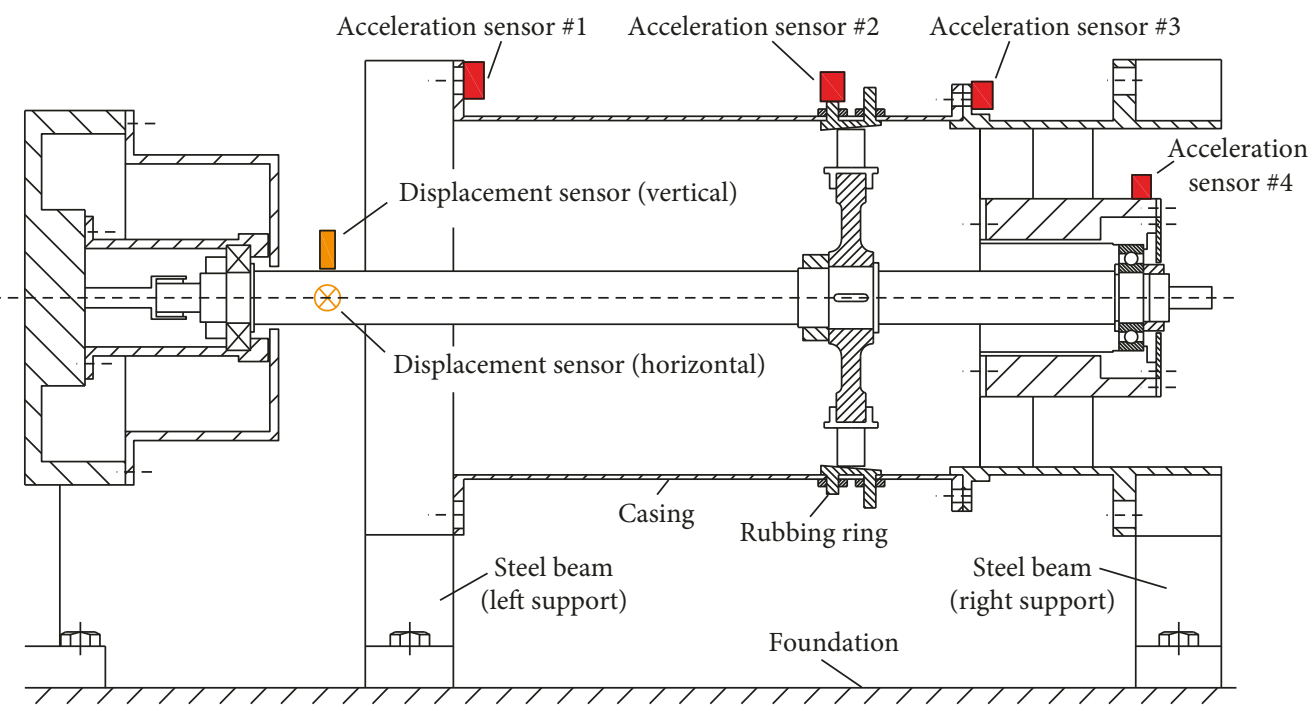

(b)
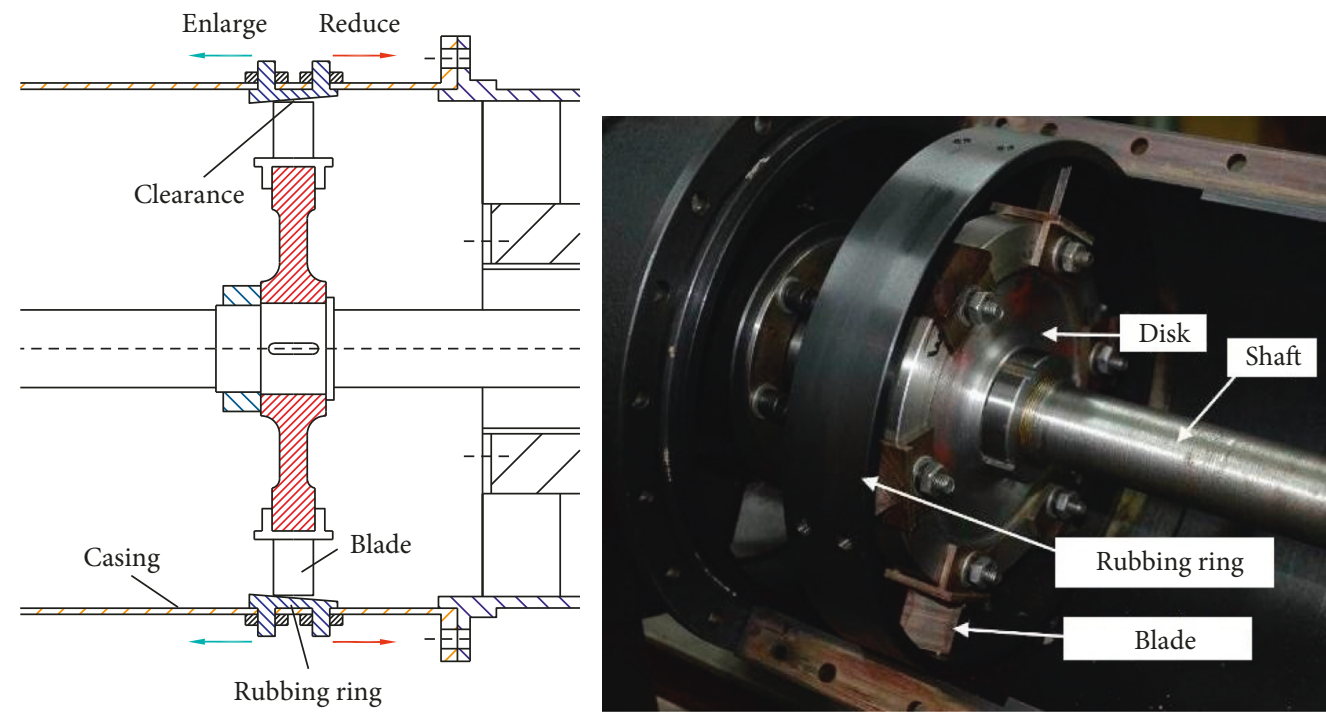

(c)

Figure 3: Test rig of rub-impact. (a) The rotor-support-casing test rig. (b) Sensor location and constraints of casing. (c) View of the rotor and the rubbing ring. 
TABLE 1: Key parameters of the rotor.

\begin{tabular}{lccccrc}
\hline & Shaft & & & Disk & & \multicolumn{2}{c}{ Blade } \\
Diameter & Span length & Diameter & Mass & Radial height & 26.0 & \\
\hline 30.0 & 542.5 & 148.0 & 2.545 & 0.0223 \\
\hline
\end{tabular}

Length: $\mathrm{mm}$; mass: kg.

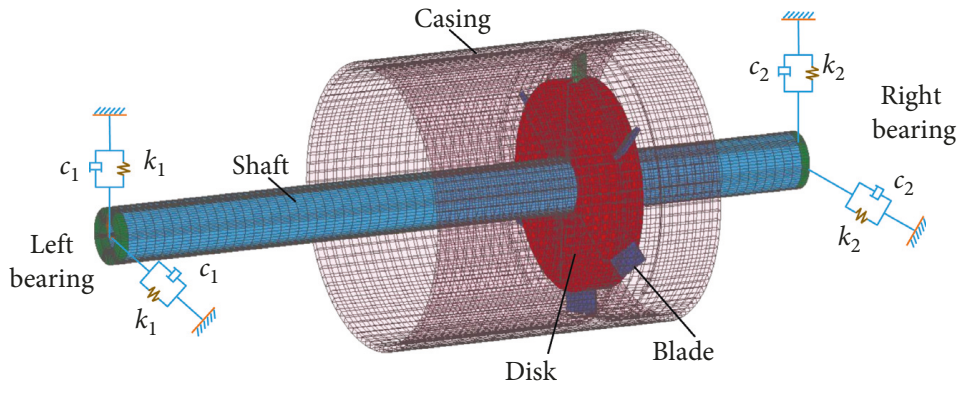

(a)

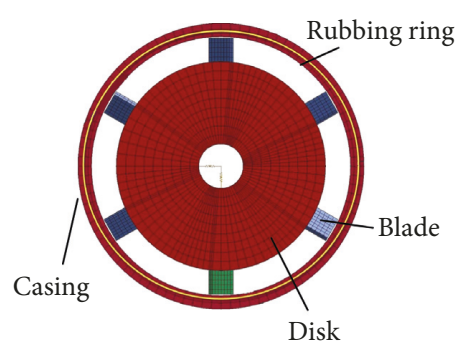

(b)

Figure 4: FE model of rub-impact. (a) Full view. (b) Section view.

set as follows: elastic modulus $E=2.1 \times 10^{11} \mathrm{~Pa}$; Poisson's ratio $\mu=0.3$; density $\rho=7800 \mathrm{~kg} / \mathrm{m}^{3}$.

The stiffness and damping of the left support were $K_{1}=$ $1 \times 10^{8} \mathrm{~N} / \mathrm{m}$ and $C_{1}=2 \times 10^{5} \mathrm{~N} \cdot \mathrm{s} / \mathrm{m}$, respectively, while that of the right support were $K_{2}=8 \times 10^{5} \mathrm{~N} / \mathrm{m}$ and $C_{2}=2 \times 10^{5} \mathrm{~N} \cdot \mathrm{s} / \mathrm{m}$. The imbalance force was generated by a heavier blade which is in green in Figure 4(b), and the imbalance was set as $2 \times 10^{-4} \mathrm{~kg} \cdot \mathrm{m}$. For other parameters, refer to Table 1.

According to the simulation, the first critical speed of the rotor system was $4090 \mathrm{r} / \mathrm{min}$ with the pitch mode shape (Figure 5(a)), and the second critical speed was $15919 \mathrm{r} / \mathrm{min}$ with the bending mode shape (Figure 5(b)). The first critical speed acquired by tests form the spectrogram of the rotor during acceleration and deceleration was $4135 \mathrm{r} / \mathrm{min}$ (Figure 6), and the relative error between simulation and test was $1 \%$.

3.2. Results of Light Rub-Impact. According to the repeated test results, light partial rub-impact usually occurred when the initial clearance was set as $0.50 \mathrm{~mm}$. The rotating speed was $1650 \mathrm{r} / \mathrm{min}(27.5 \mathrm{~Hz})$. As shown in Figure $7(\mathrm{a})$, a scratch with $2 \mathrm{~mm}$ width, $36^{\circ}$ on circumferential direction could be observed on the inner surface of the rubbing ring. The Von Mises stress distribution is shown in Figure 7(b), and the max stress 196.2 MPa is located at the tip of the blade which rubbed against the casing.

The results of the experiments (Figures 8(a) and 9(a)) and simulation (Figures 8(b) and 9(b)) show good agreements on the shape of the rotor orbits and the frequency domain responses. The orbits were polygonal in shape, and the motion of the rotor was stable under light rub-impact condition. It could be observed that the synchronous component occupied a dominant position, while super harmonics with small amplitude existed.
Figure 10(a) shows the experimental acceleration response which was measured by acceleration sensor 2\#. Figure 10(b) shows the numerical nondimensional force on the rubbing ring. The contact was not continuous, and the rub-impact between the rotor and the rubbing ring was intermittent. There were 6 peaks in 0.2 seconds, and the contact frequency was about $30 \mathrm{~Hz}$ which was close to the rotating speed frequency.

3.3. Results of Heavy Rub-Impact. The clearance between the blade and the casing was changed to $0.30 \mathrm{~mm}$, and the heavy partial rub-impact occurred at the same rotating speed. A scratch with $10 \mathrm{~mm}$ width, $90^{\circ}$ on circumferential direction could be observed after the test, and the wear on the tip of one blade was obvious (shown as Figure 11(a)). According to the simulation (Figure 11(b)), two blades were rubbing the casing at the same time with the max Von Mises stress 273.3 $\mathrm{MPa}$ on the tip.

The comparison of the results of experiments and simulation under the heavy rub-impact condition are summarized in Figures 12-14. The main response characteristics of simulation could coincide with the tests. In contrast to the light rub-impact condition, Figure 12 shows the vibration amplitude had a significant increase, and the shape of orbits were more complex. As shown in Figure 13, the amplitude of the super harmonics component, especially the $3 \mathrm{x}$ rotating speed frequency component, was obvious. Figure 14 illustrates that there were 10 peaks in 0.2 seconds, and the numerical results were in good agreement with the experimental results.

The results show that (1) the prediction of the response of the rub-impact rotor is more complex under the heavy rubimpact condition due to the strong nonlinearity; (2) the simulation model is able to reproduce the main response 


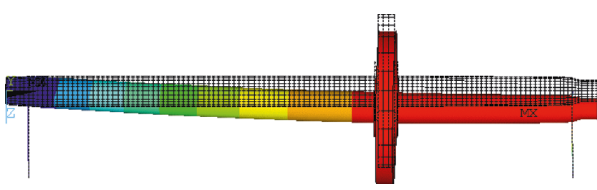

(a)

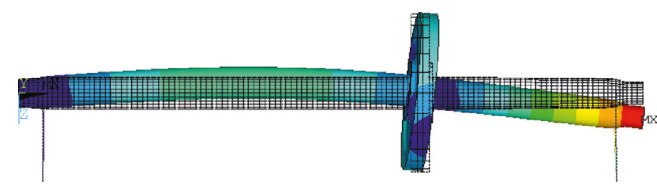

(b)

Figure 5: Mode shapes of the rotor. (a) Pitch. (b) Bending.

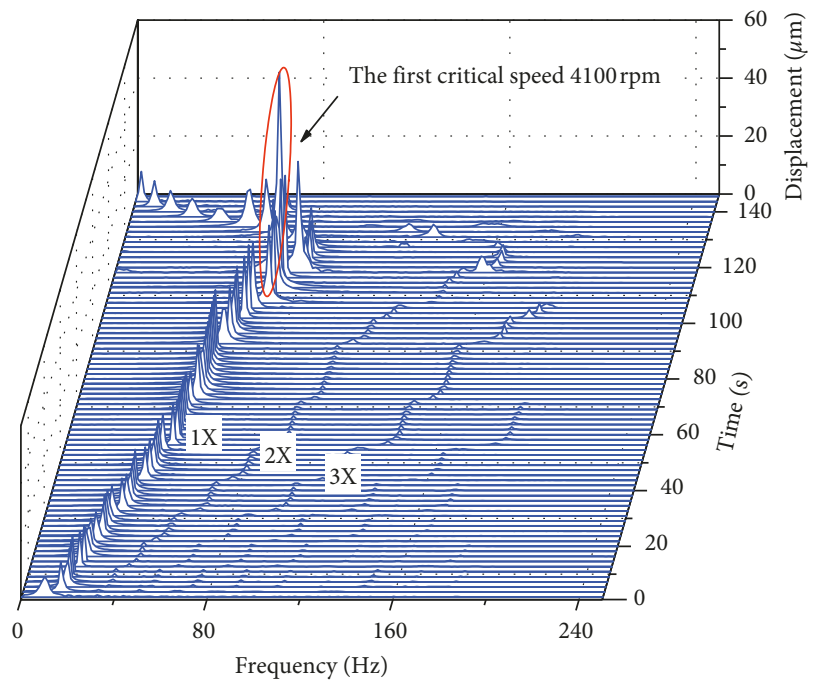

FIGURE 6: Spectrogram of rotor during acceleration and deceleration.

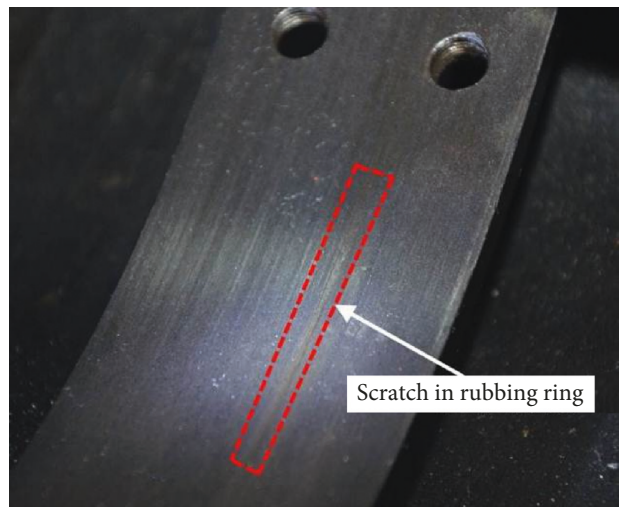

(a)

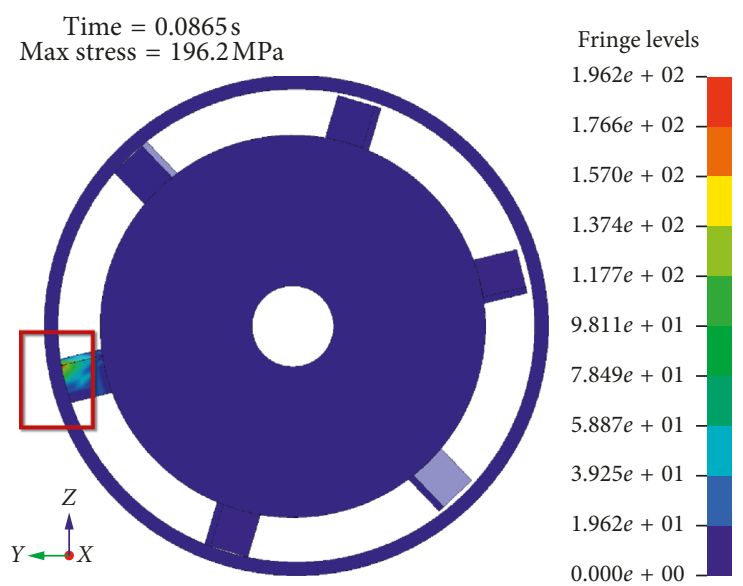

(b)

FIgURE 7: Results of light rub-impact condition. (a) Scratch on rubbing ring. (b) Von Mises stress distribution.

characteristics; (3) the method proposed in this paper can be used to simulate the process of rub-impact.

\section{Simulation of Blade-Casing Rub-Impact}

The transient process of the rub-impact between the blade and casing was simulated based on the actual structure of the aeroengine. The effects of the major physical parameters including imbalance and material characteristics were investigated.
4.1. Analysis Model. The sketch of an actual turbine bladecasing system is shown in Figure 15(a). Based on the structure, the FE model was established as shown in Figure 15(b). The turbine disk was simplified as equivalent one in consideration of the supporting bearing stiffness. The casing was constrained in the radial and axial direction at the edge. Parameters of the model are as follows: diameter of the casing $d=215 \mathrm{~mm}$; thickness of the casing $t=2.2 \mathrm{~mm}$; number of blades $n=18$; height of blade $h=26 \mathrm{~mm}$; initial clearance $\delta=1.2 \mathrm{~mm}$; rotating speed $\omega=12500 \mathrm{r} / \mathrm{min}$, 


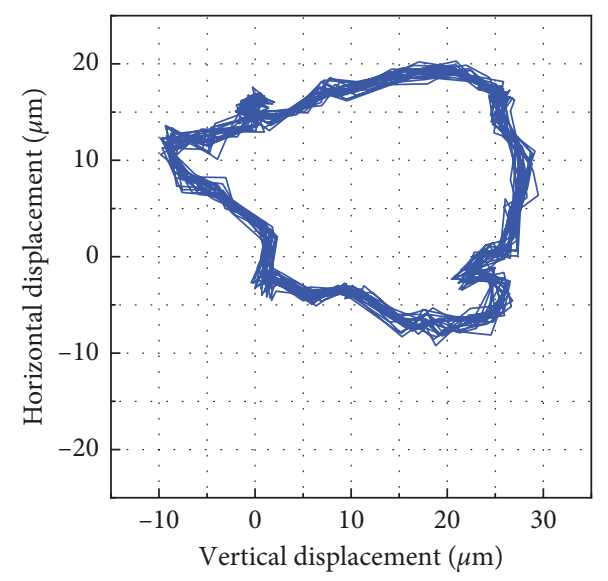

(a)

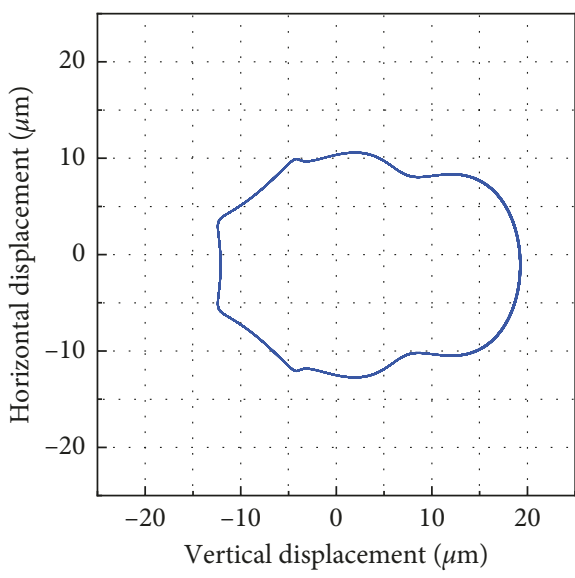

(b)

Figure 8: Comparison of the orbits under light rub-impact condition. (a) Experimental result. (b) Numerical result.

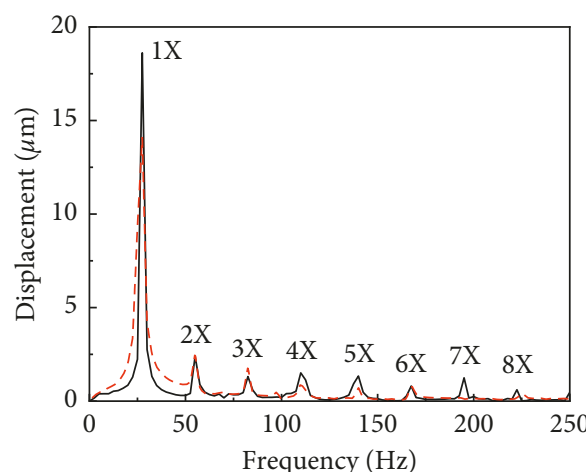

- Vertical direction

- - - Horizontal direction

(a)

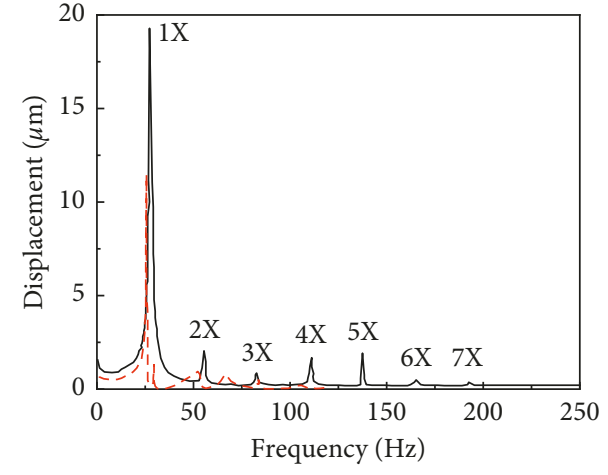

- Vertical direction

- - - Horizontal direction

(b)

FiguRE 9: Comparison of dynamic response in frequency domain under light rub-impact condition. (a) Experimental result. (b) Numerical result.

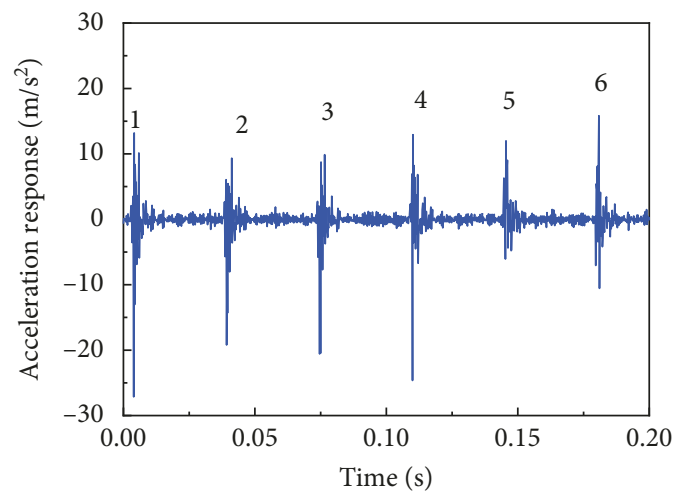

(a)

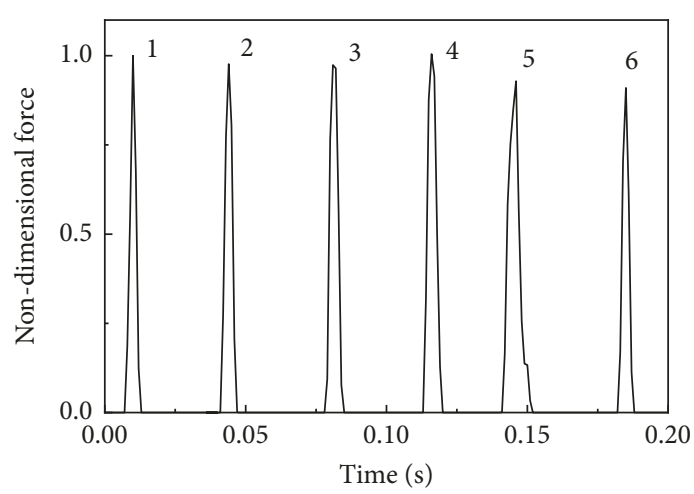

(b)

FIgURE 10: Acceleration response and nondimensional force on the rubbing ring under light rub-impact condition. (a) Experimental acceleration response. (b) Numerical nondimensional force. 


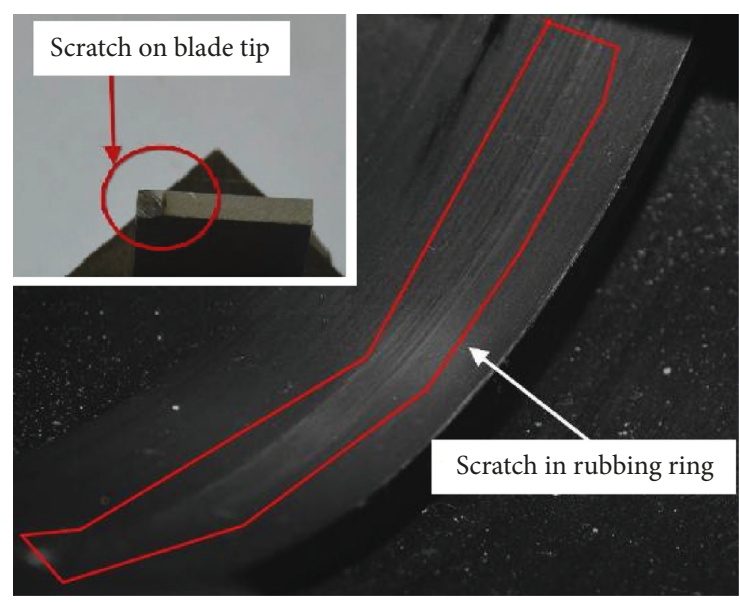

(a)

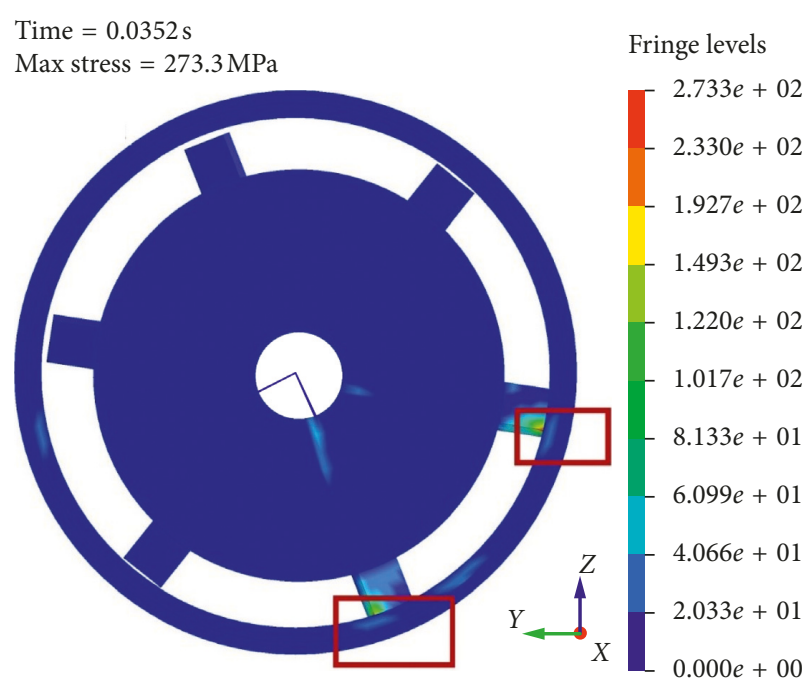

(b)

Figure 11: Results of heavy rub-impact condition. (a) Scratch on rubbing ring and blade. (b) Von Mises stress distribution.

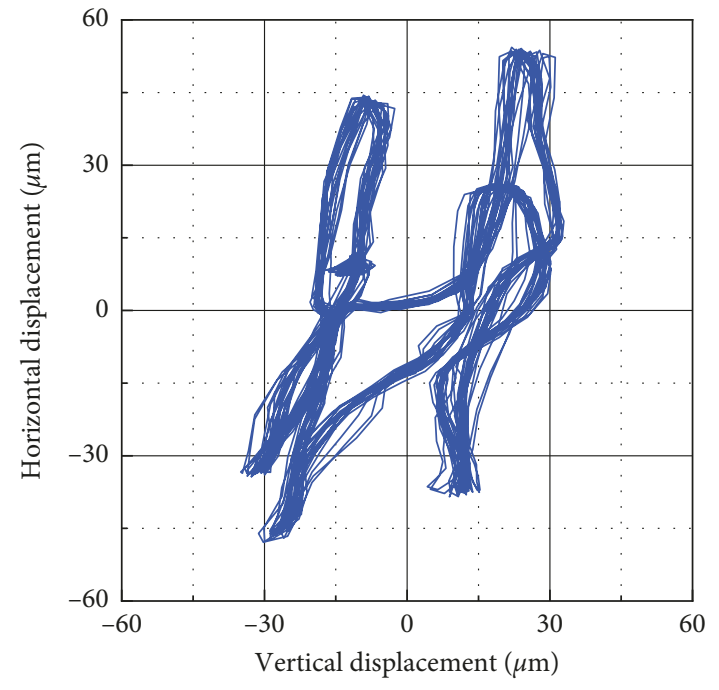

(a)

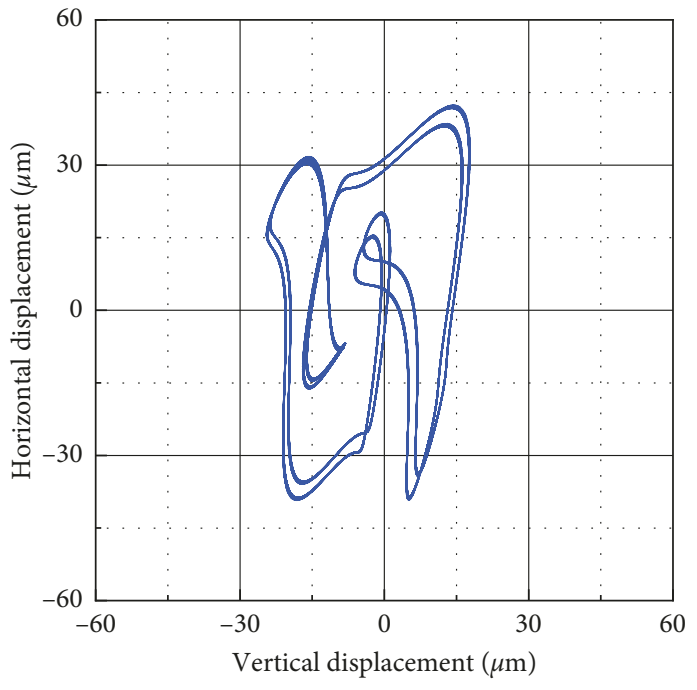

(b)

FIGURE 12: Comparison of the orbits under heavy rub-impact condition. (a) Experimental result. (b) Numerical result.

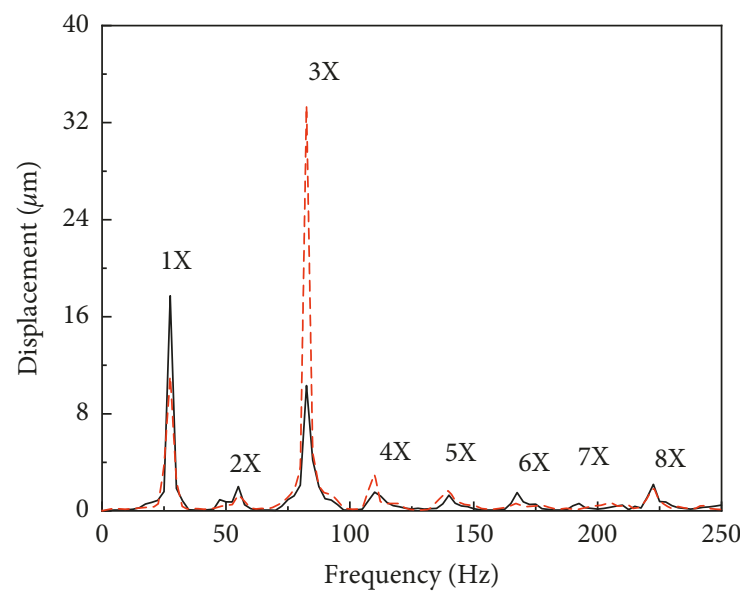

(a)

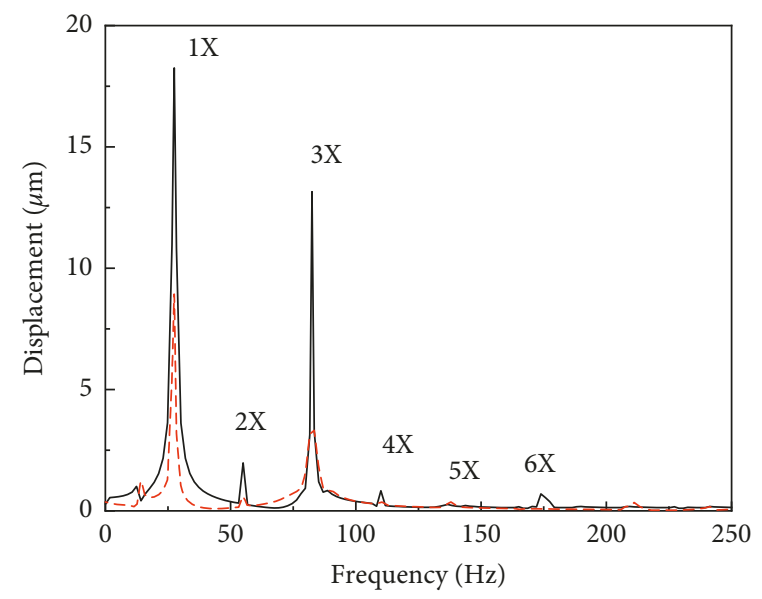

(b)

Figure 13: Comparison of dynamic response in frequency domain under heavy rub-impact condition. (a) Experimental result. (b) Numerical result. 


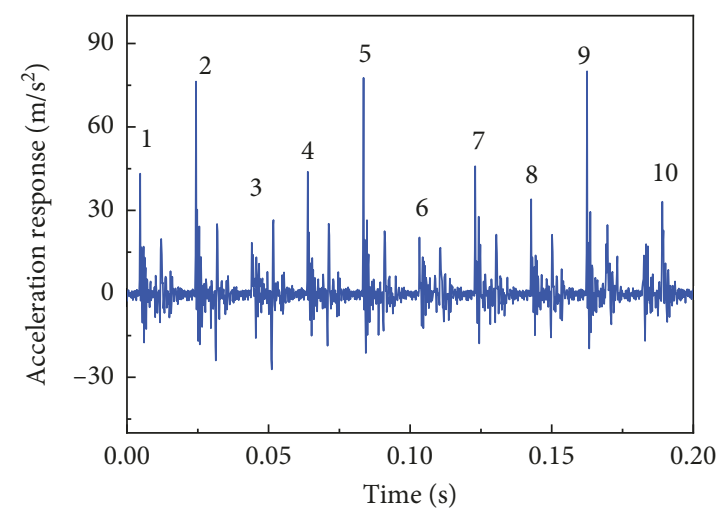

(a)

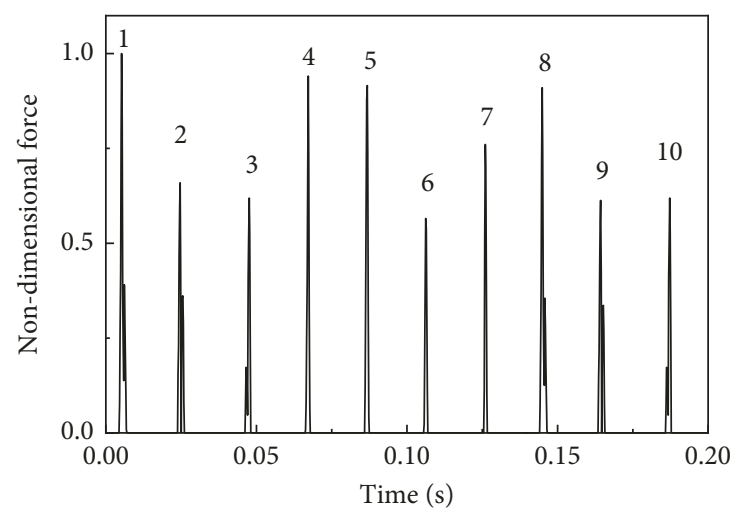

(b)

Figure 14: Acceleration response and nondimensional force on rubbing ring under heavy rub-impact condition. (a) Experimental acceleration response. (b) Numerical nondimensional force.

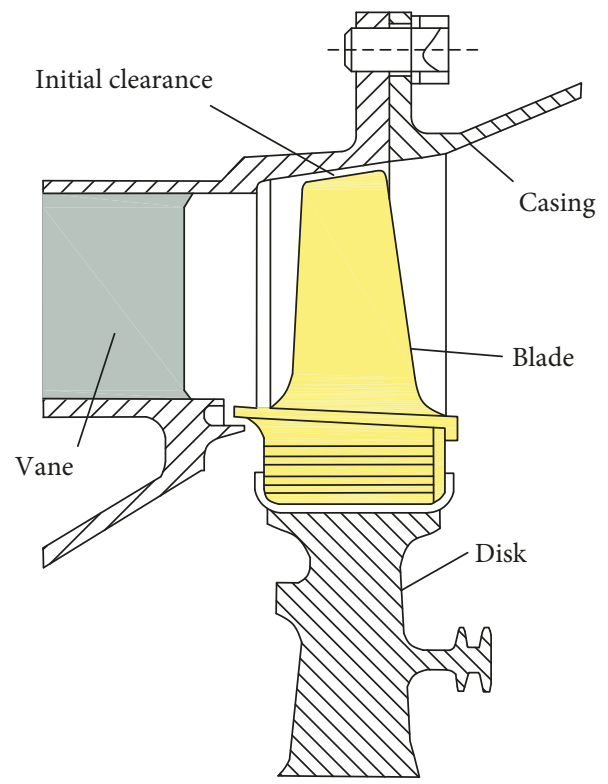

(a)

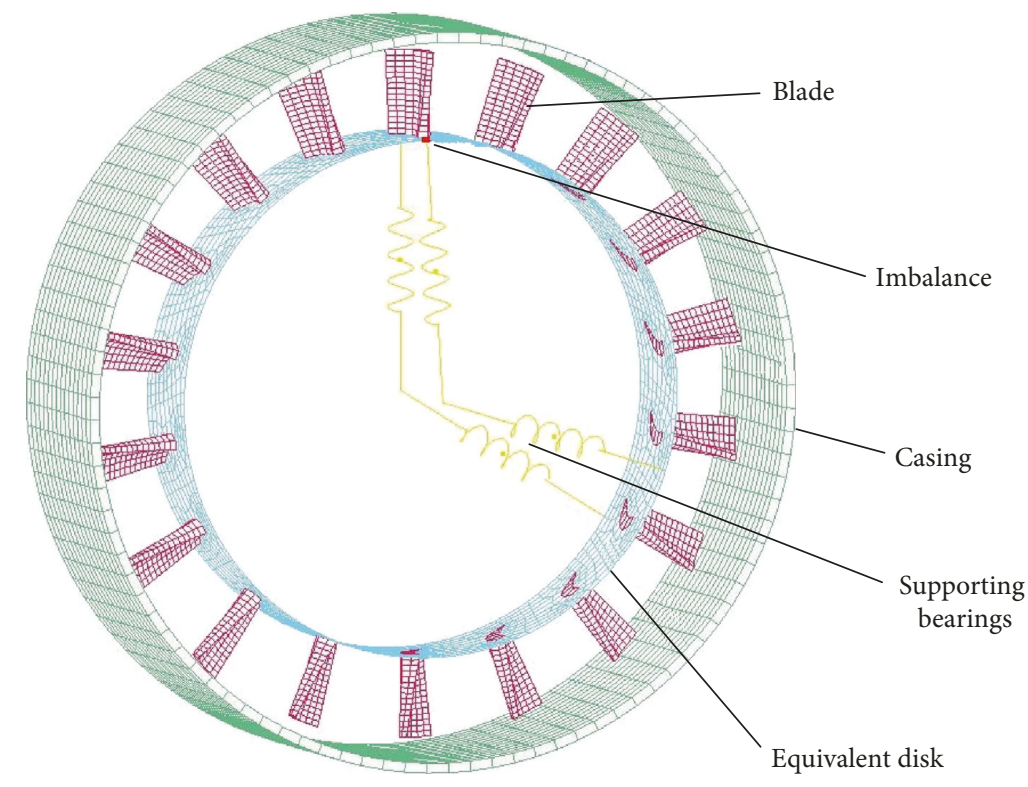

(b)

FIGURE 15: Analysis model of an actual turbine blade-casing system. (a) Sketch. (b) FE model.

imbalance which is simulated by mass element $u=10 \mathrm{~g} \cdot \mathrm{cm}$; supporting bearing stiffness and damping $K=4 \times$ $10^{7} \mathrm{~N} / \mathrm{m}, C=2 \times 10^{3} \mathrm{~N} \cdot \mathrm{s} / \mathrm{m}$; friction coefficient between blades and casing $\mu=0.25$. Material parameters are listed in Table 2 .

\subsection{Response Characteristics}

4.2.1. Rub-Impact Process. Numerical simulation results are shown in Figure 16, with the pictures displaying the typical states of the blades. The rub-impact occurred twice in $2000 \mu \mathrm{s}$.

According to the results, the blade tips suffered from both the radial impact force and the tangential friction force at the initial stage of the rub-impact process, and the maximum stress was at the blade tip. However, the maximum stress moved to the blade root at the end of the rub-impact process due to the conduction of the stress wave generated by the impact.

4.2.2. Response of Blade. During the rub-impact process, the main focus is the time history response of the stress distribution of the rubbing blade. The radial stress distribution of the blade which firstly rubbed against the casing was analyzed. The time history radial stresses of the elements at the tip, middle, and root of the trailing edge of the blade are shown in Figure 17.

In Figure 17, the initial stress before time A was generated by the centrifugal force. Once the rub-impact occurs, the radial stress of the blade varies rapidly. The elements at the tip and root of the blade were subjected to the tensile stress, while the element at the middle of the blade was 
TABLE 2: Material parameters in the FE model of blade-casing system.

\begin{tabular}{lccccc}
\hline Structure & Density $\left(\mathrm{kg} / \mathrm{m}^{3}\right)$ & Elastic modulus $(\mathrm{Pa})$ & Poisson ratio & Yield stress $(\mathrm{Pa})$ & Tangent modulus \\
\hline Blade & 7870 & $2.05 \times 10^{11}$ & 0.33 & $8.00 \times 10^{8}$ & $0.95 \times 10^{8}$ \\
Casing & 8240 & $1.99 \times 10^{11}$ & 0.30 & $8.68 \times 10^{8}$ & $1.12 \times 10^{8}$ \\
\hline
\end{tabular}

(a)

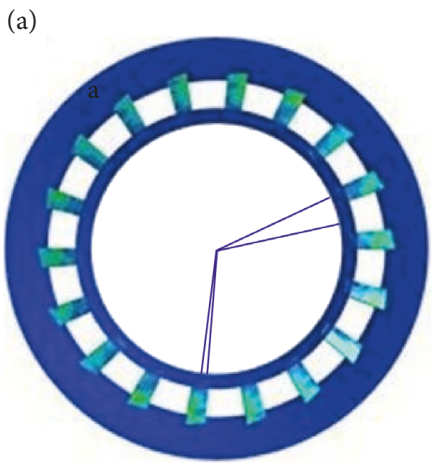

Normal operation (b)

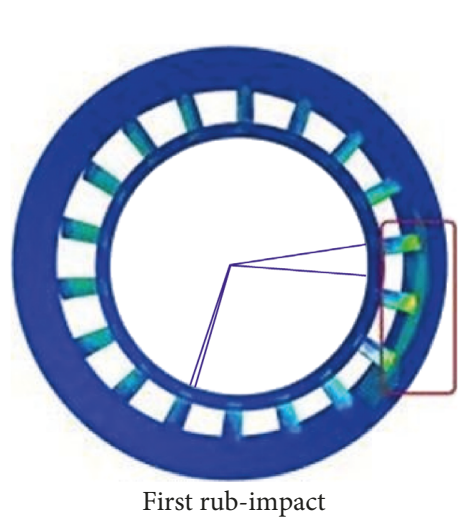

(c)

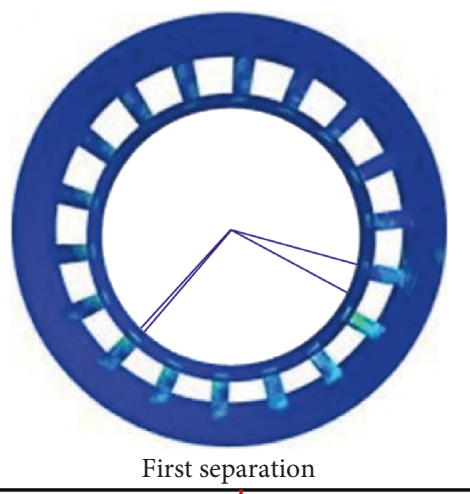

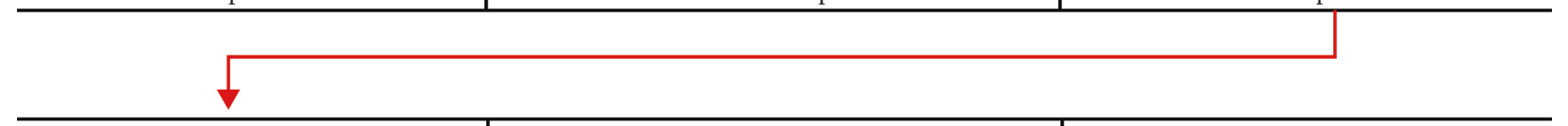

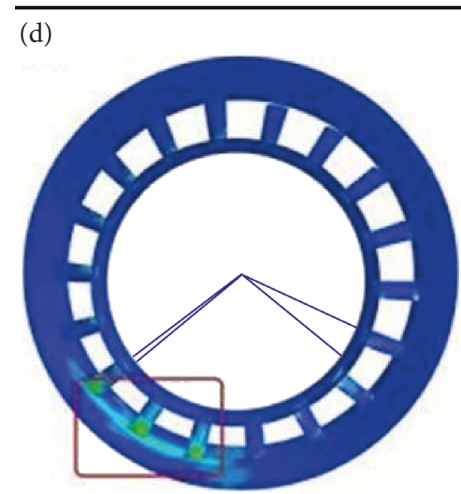

Second rub-impact

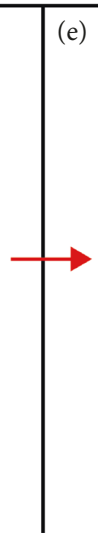

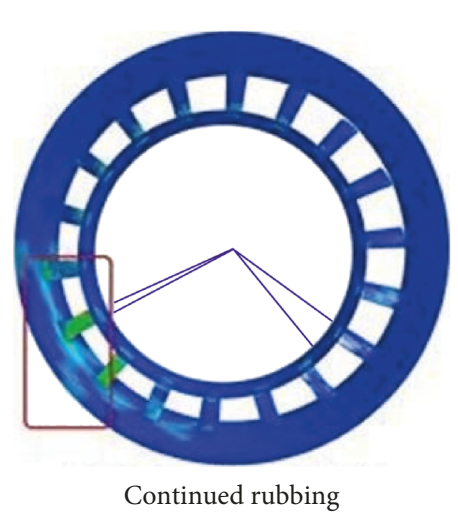
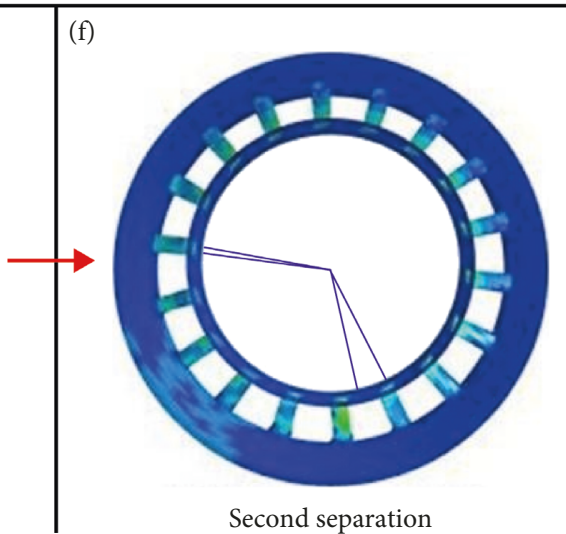

Figure 16: Rub-impact process during $2000 \mu$ s shown in Von Mises stress.

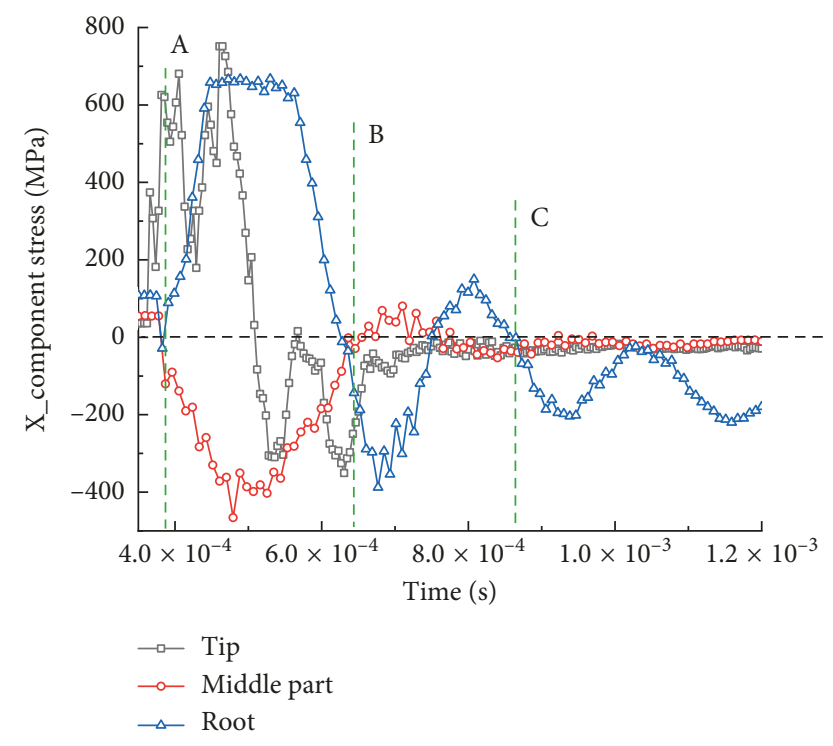

Figure 17: Time history of the radial stress on rubbing blade. subjected to the compressive stress. The stresses at the tip, middle, and root of the blade reached their maximum values in sequence after the rub-impact occurred. Figure 18 gives the distribution of radial stress at different locations and different moments, and the conduction of stress could be observed easily.

The highest stress was at the blade tip when the rubimpact occurred, and then the part with maximum stress moved to the blade root while the amplitude attenuated. Therefore, in some rub-impact faults, the maximum transient stress at the blade tip was usually higher than the ultimate strength of the material.

4.2.3. Response of Casing. The rub-impact force which depends on the materials and the relative movements of the blade and casing was calculated by summation of the resultant force of all nodes at the contact surface of the casing. The normalized rub-impact force was used to analyze and compare the relative magnitude of the two rub-impact processes. 


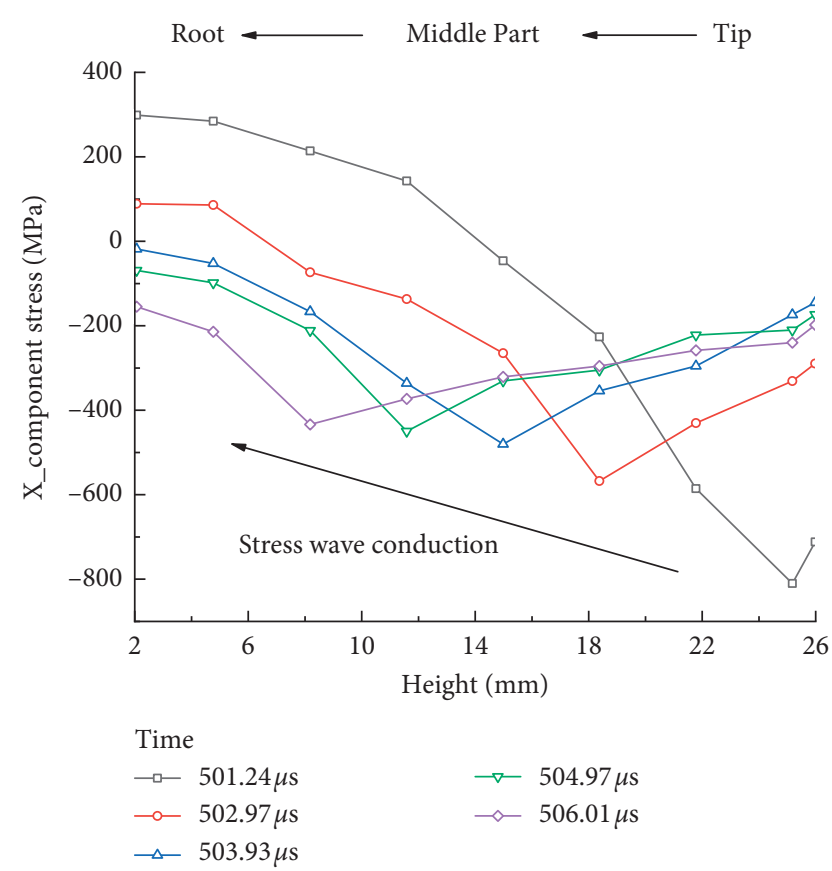

FIGURE 18: Distribution of the radial stress on different positions of rubbing blade.

Figure 19 demonstrates that the time of each rub-impact is short enough. The first rub-impact process generated a more obvious impact effect with a shorter contact time $\left(\Delta t_{1}<\Delta t_{2}\right)$, which means the rotor and the stator departed from each other rapidly, and the scratch area was relatively small. The impact effect of the second rub-impact process was weaker, and the high level rub-impact loads lasted a relatively longer time $\left(\Delta t_{4}>\Delta t_{3}\right)$. The static friction force would generate between the rotor and the stator, and the rub-impacted area was larger. The different response was caused by the different relative motion of the rotor and stator (the relative velocity and acceleration).

4.3. Parameter Influences. The influence of imbalance and material parameters of the blade and casing on the response was analyzed.

4.3.1. Imbalance. Rotating speed was $12500 \mathrm{r} / \mathrm{min}(208 \mathrm{~Hz})$, and the responses of the model with different imbalances $(2.0 \mathrm{~g} \cdot \mathrm{cm}$ and $20.0 \mathrm{~g} \cdot \mathrm{cm})$ were simulated, while the other parameters were same with that of the FE model in Figure 15 and Table 2. The normalized contact force is shown in Figure 20. It should be noticed that the reference max contact force is the same with that in Figure 19.

When the imbalance was $2.0 \mathrm{~g} \cdot \mathrm{cm}$, the rub-impact occurred only once in $0.002 \mathrm{~s}$, and the maximum value of the nondimensional force was about 0.035 . When the imbalance increased to $20.0 \mathrm{~g} \cdot \mathrm{cm}$, the rub-impact occurred twice in $0.002 \mathrm{~s}$, and the maximum value of the force reached to 1.479. The intensity of rub-impact improved and the duration of every impact increased.

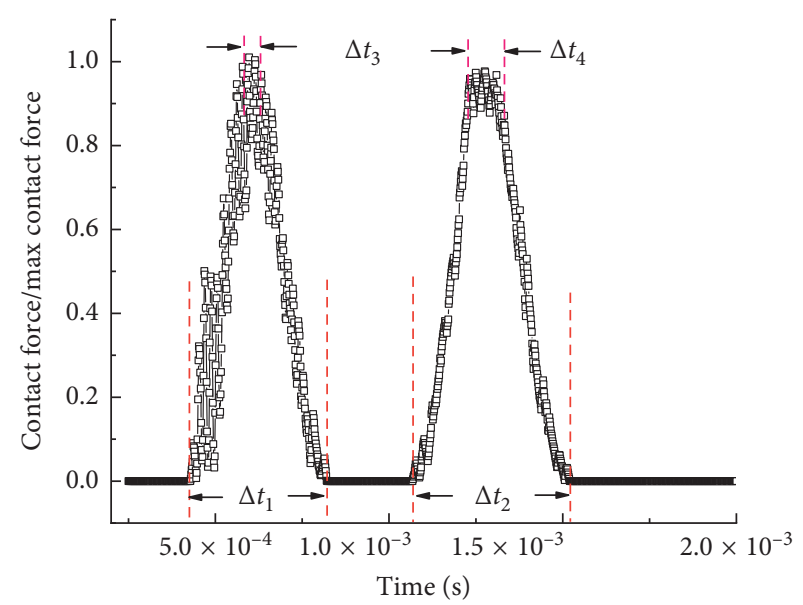

FIGURE 19: Time history response of the contact force on the casing.

\subsubsection{Material Parameters.}

(1) Yield Strength. The yield strength of blade material decreases with the increase of turbine temperature [31]. The yield strength of the blade was set as $80 \%$ of the original value. Calculation results showed the main characteristics of the response were similar to those in Figure 16, while the value of the stress on the blades and casing varied. As illustrated in Figure 21, the maximum value of the stress decreased as the yield strength reduced. An easier deformation occurred on the impact blade tip.

The time history response of the contact force is shown in Figure 22. It could be observed that the peak value of the contact force decreased while the bandwidth of the peak force $\left(\Delta t_{1}\right.$ and $\left.\Delta t_{2}\right)$ increased compared to that in Figure 19, which indicated that the deformation of the blade tip increased.

(2) Young's Modulus. For alloy materials, Young's modulus decreases with the increase of turbine temperature [32]. Together with the erosion of sea salt on blade materials, Young's modulus may be reduced by $50 \%$. Material Young's modulus of the blades was set as $50 \%$ of the original value. Due to decrease of Young's modulus, stiffness of the blades reduced which would lead to a larger deformation and equivalent stress on the blades. Meantime, the natural frequency decreased, which was caused by compressive loads [33]. The variation could be observed from Figure 23.

The deformation and stress at the blade tip increased obviously with the decrease of Young's modulus, and the stress concentration on blade tips enhanced. In Figure 24 is shown the time history response of radial stress on the root of the blade; the maximum value decreased while the time $t_{\mathrm{AB}}$ with high stress increased. The decay time $t_{\mathrm{BC}}$ that the free vibration needs to be stable was shorter. The results showed the blade with weaker stiffness (lower natural frequency) responded less obviously to the free vibration excited by rub-impact.

The wave shape in Figure 25 is almost the same as that in Figure 19, while the peak value of the rub-impact force decreased about $10 \%$ and the bandwidth of the rub-impact 


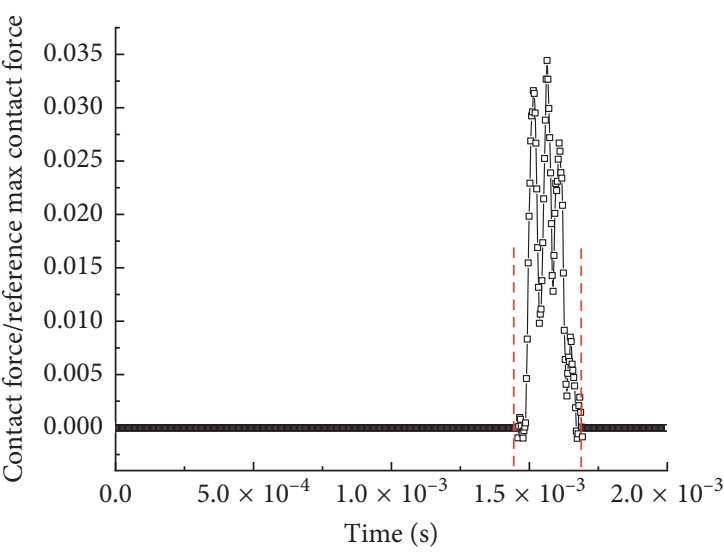

(a)

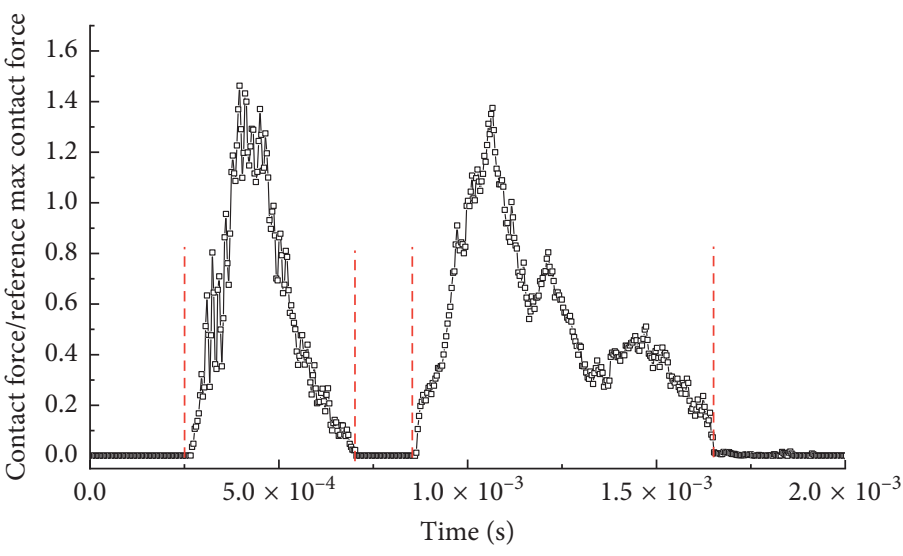

(b)

Figure 20: Comparison of the contact force on the casing in different imbalances: (a) $2.0 \mathrm{~g} \cdot \mathrm{cm}$; (b) $20.0 \mathrm{~g} \cdot \mathrm{cm}$.

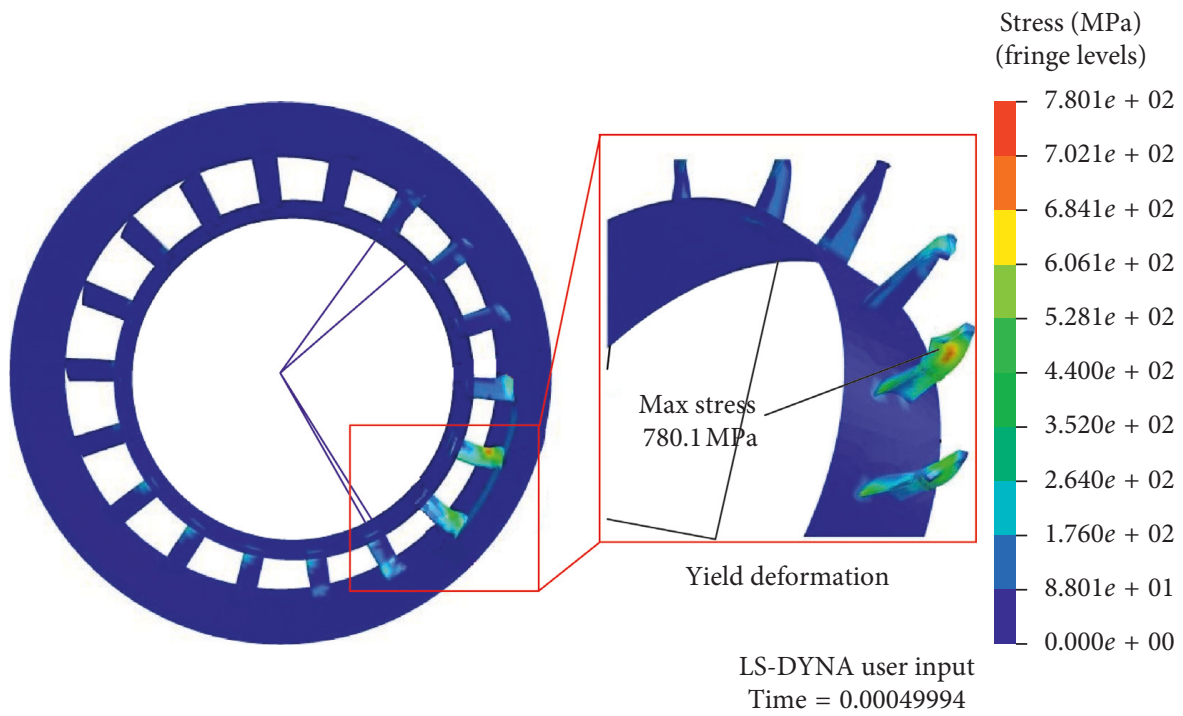

Figure 21: Distribution of Von Mises stress with lower yield strength.

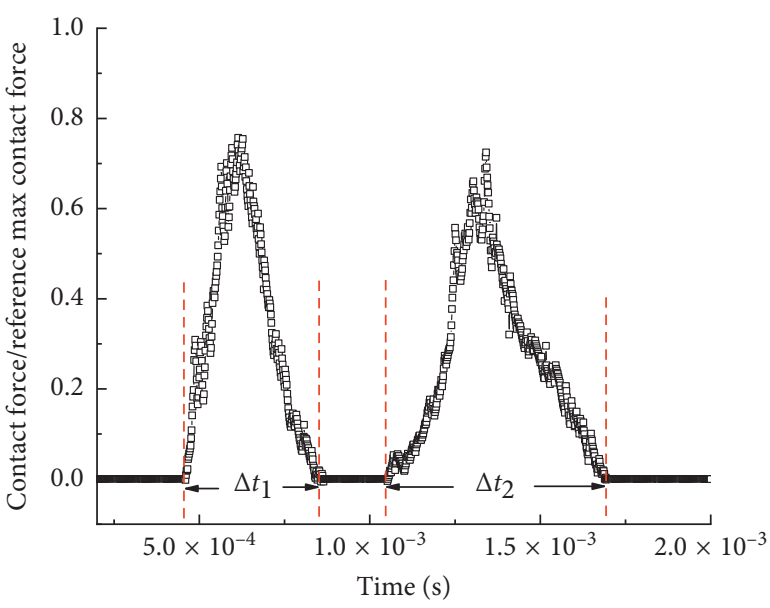

FIGURE 22: Time history of the contact force on the casing with lower yield strength. force increased slightly. The result demonstrated that the partial deformation of the blade, area of scratch, and time of contact increased with lower Young's modulus.

\section{Conclusions}

A theoretical model was established to describe the rotorsupport-casing system in aeroengines, while the nonlinear equations were solved through the symmetric penalty-based approach. The suggested procedure relying on the finite element method was applied on a test rig to simulate the characteristics of light and heavy rub-impact. Rub-impact simulation of the blade-casing model was also conducted. It is possible to draw the following conclusions:

(1) The test rig could simulate the different rub-impact condition, while the numerical method proposed 


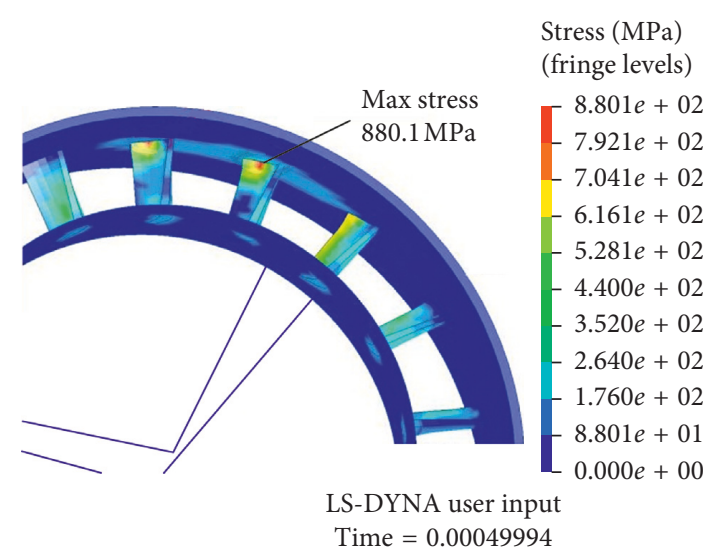

(a)

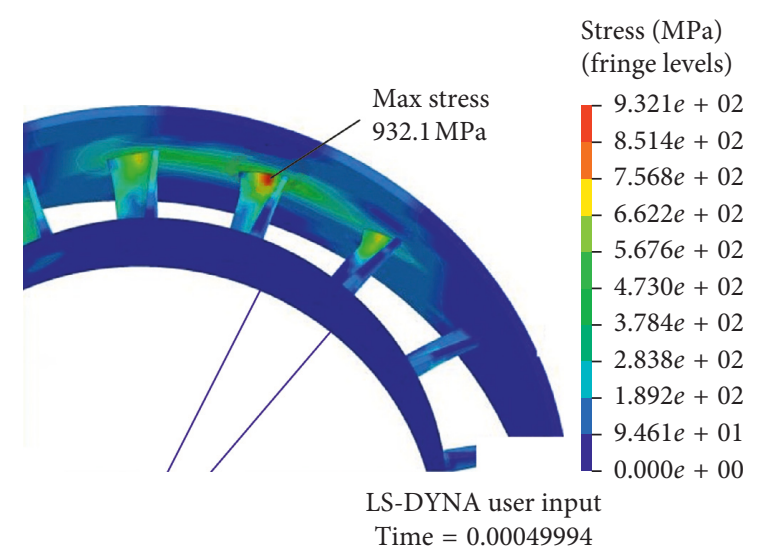

(b)

FIGURE 23: Distribution of Von Mises stress with lower Young's modulus. (a) Initial Young's modulus. (b) 50\% Young's modulus.

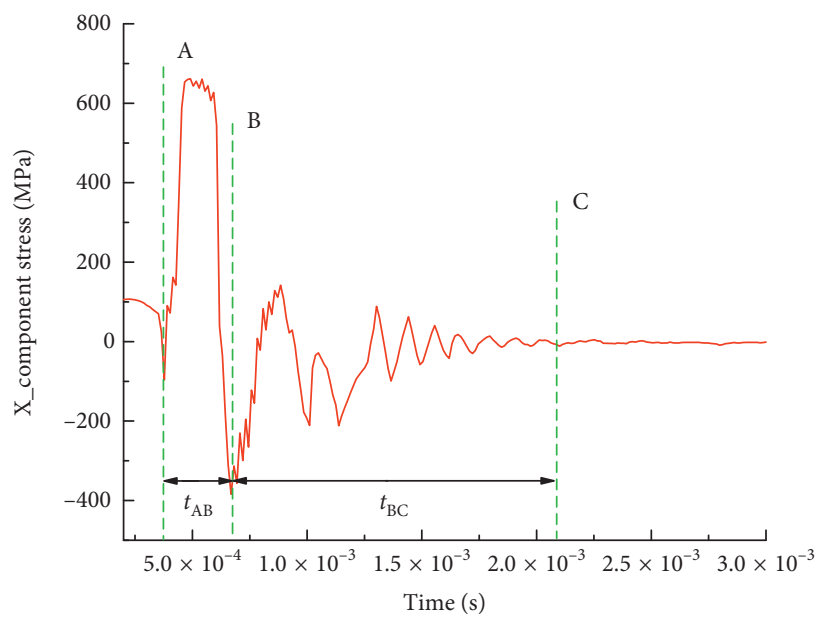

(a)

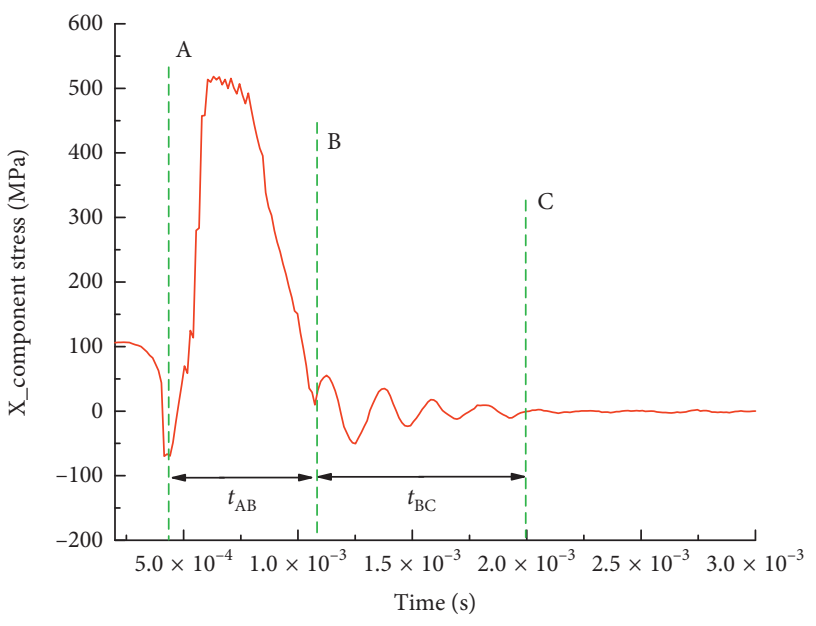

(b)

Figure 24: Comparison of the radial stress on the root of blade in different Young's modulus. (a) Initial Young's modulus. (b) 50\% Young's modulus.

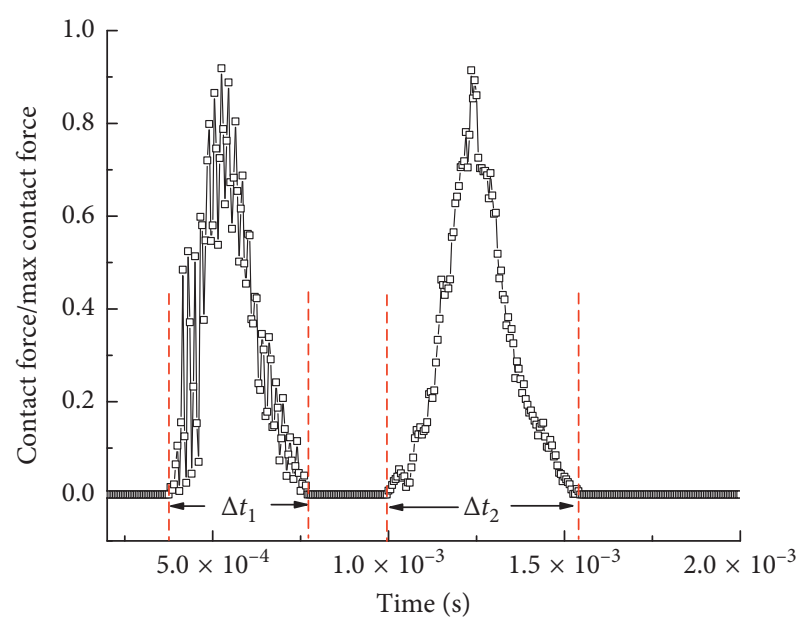

FIGURE 25: Time history of the contact force on the casing with lower Young's modulus. could reproduce the main characteristics during the rub-impact process of an actual structure.

(2) During the rub-impact, the highest stress first occurs at the blade tip, and then the part with maximum stress moves to the blade root while the amplitude attenuates. Therefore, in some rub-impact faults, the maximum transient stress at the blade tip is usually higher than the ultimate strength of the material.

(3) The maximum value of the stress decreases as the yield strength reduces, which may lead to an easier deformation on the blade tip. With weaker stiffness, the stress concentration at the blade tip, partial deformation, area of scratch, and time of contact increase during the rub-impact process.

The description of rub and impact and influence of damping factor are still practical limitations in this study. Further research studies will be devoted to remove these 
limitations and improve the accuracy of quantitative analysis.

\section{Data Availability}

The data used to support the findings of this study are available from the corresponding author upon request.

\section{Conflicts of Interest}

The authors declare that there are no conflicts of interest regarding the publication of this paper.

\section{Acknowledgments}

The authors would like to acknowledge the financial support from the National Natural Science Foundation of China (Grant nos. 51575022 and 51475021).

\section{References}

[1] R. E. Chupp, R. C. Hendricks, S. B. Lattime, and B. M. Steinetz, "Sealing in turbomachinery," Journal of Propulsion and Power, vol. 22, no. 2, pp. 313-349, 2006.

[2] H. Ma, F. Yin, Y. Guo, X. Tai, and B. Wen, "A review on dynamic characteristics of blade-casing rubbing," Nonlinear Dynamics, vol. 84, no. 2, pp. 437-472, 2015.

[3] A. Muszynska, "Rotor-to-stationary element rub-related vibration phenomena in rotating machinery-literature survey," Shock and Vibration Digest, vol. 3, no. 21, pp. 3-11, 1989.

[4] S. Ahmad, "Rotor casing contact phenomenon in rotor dynamics-literature survey," Journal of Vibration and Control, vol. 16, no. 9, pp. 1369-1377, 2010.

[5] G. Jacquet-Richardet, M. Torkhani, P. Cartraud et al., "Rotor to stator contacts in turbomachines. Review and application," Mechanical Systems and Signal Processing, vol. 40, no. 2, pp. 401-420, 2013.

[6] E. V. Karpenko, M. Wiercigroch, E. E. Pavlovskaia, and R. D. Neilson, "Experimental verification of Jeffcott rotor model with preloaded snubber ring," Journal of Sound and Vibration, vol. 298, no. 4-5, pp. 907-917, 2006.

[7] Z. C. Feng and X.-Z. Zhang, "Rubbing phenomena in rotorstator contact," Chaos, Solitons \& Fractals, vol. 14, no. 2, pp. 257-267, 2002.

[8] S. K. Sinha, "Dynamic characteristics of a flexible bladed-rotor with Coulomb damping due to tip-rub," Journal of Sound and Vibration, vol. 273, no. 4-5, pp. 875-919, 2004.

[9] A. Batailly, M. Legrand, P. Cartraud et al., "Study of component mode synthesis methods in a rotor-stator interaction case," in Proceedings of ASME International Design Engineering Technical Conferences \& Computers and Information in Engineering Conference (IDETC CIE 2007), pp. 1235-1242, Las Vegas, NV, USA, September 2007.

[10] C. Villa, J.-J. Sinou, and F. Thouverez, "Stability and vibration analysis of a complex flexible rotor bearing system," Communications in Nonlinear Science and Numerical Simulation, vol. 13, no. 4, pp. 804-821, 2008.

[11] M. Legrand, C. Pierre, P. Cartraud, and J.-P. Lombard, "Twodimensional modeling of an aircraft engine structural bladed disk-casing modal interaction," Journal of Sound and Vibration, vol. 319, no. 1-2, pp. 366-391, 2009.
[12] H. Ma, X. Tai, H. Niu et al., "Numerical research on rubimpact fault in a blade-rotor casing coupling system," Journal of Vibroengineering, vol. 15, no. 3, pp. 1477-1489, 2013.

[13] S. K. Sinha, "Rotordynamic analysis of asymmetric turbofan rotor due to fan blade-loss event with contact-impact rub loads," Journal of Sound and Vibration, vol. 332, no. 9, pp. 2253-2283, 2013.

[14] H. M. Khanlo, M. Ghayour, and S. Ziaei-Rad, "Chaotic Vibration Analysis of rotating flexible continuous shaft disk system with a rub-impact between the disk and the stator," Communications in Nonlinear Science and Numerical Simulation, vol. 16, no. 1, pp. 566-582, 2013.

[15] C.-M. Liao, B. Balachandran, M. Karkoub, and Y. L. AbdelMagid, "Drill-string dynamics: reduced-order models and experimental studies," Journal of Vibration and Acoustics, vol. 133, no. 4, article 041008, 2011.

[16] P. Pennacchi, N. Bachschmid, and E. Tanzi, "Light and short arc rubs in rotating machines: experimental tests and modelling," Mechanical Systems and Signal Processing, vol. 23, no. 7, pp. 2205-2227, 2009.

[17] F. Chu and W. Lu, "Experimental observation of nonlinear vibrations in a rub-impact rotor system," Journal of Sound and Vibration, vol. 283, no. 3-5, pp. 621-643, 2005.

[18] M. Torkhani, L. May, and P. Voinis, "Light, medium and heavy partial rubs during speed transients of rotating machines: numerical simulation and experimental observation," Mechanical Systems and Signal Processing, vol. 29, no. 1, pp. 45-66, 2012.

[19] B. Li, H. Ma, J. Zeng, X. Guo, and B. Wen, "Rotating bladecasing rubbing simulation considering casing flexibility," International Journal of Mechanical Sciences, vol. 148, no. 10, pp. 118-134, 2018.

[20] Y. Yang, D. Cao, D. Wang, and G. Jiang, "Fixed-point rubbing characteristic analysis of a dual-rotor system based on the Lankarani-Nikravesh model," Mechanism and Machine Theory, vol. 103, pp. 202-221, 2016.

[21] Y. Yang, D. Cao, T. Yu, D. Wang, and C. Li, "Prediction of dynamic characteristics of a dual-rotor system with fixed point rubbing-Theoretical analysis and experimental study," International Journal of Mechanical Sciences, vol. 115-116, pp. 253-261, 2016.

[22] H. Ma, X. Tai, Q. Han, Z. Wu, D. Wang, and B. Wen, "A revised model for rubbing between rotating blade and elastic casing," Journal of Sound and Vibration, vol. 337, pp. 301-320, 2015.

[23] H. Ma, F. Yin, Z. Wu, X. Tai, and B. Wen, "Nonlinear vibration response analysis of a rotor-blade system with bladetip rubbing," Nonlinear Dynamics, vol. 84, no. 3, pp. 12251258, 2016.

[24] Q. Sun, H. Ma, Y. Zhu, Q. Han, and B. Wen, "Comparison of rubbing induced vibration responses using varying-thicknesstwisted shell and solid-element blade models," Mechanical Systems and Signal Processing, vol. 108, pp. 1-20, 2018.

[25] H. Ma, Y. Lu, Z. Wu, X. Tai, and B. Wen, "Vibration response analysis of a rotational shaft-disk-blade system with blade-tip rubbing," International Journal of Mechanical Sciences, vol. 107, pp. 110-125, 2016.

[26] F. Nyssen and A. Batailly, "Thermo-mechanical modeling of abradable coating wear in aircraft engines," Journal of Engineering for Gas Turbines and Power, vol. 141, no. 2, article 021031, 2019.

[27] G. Chen, "Study on the recognition of aero-engine bladecasing rubbing fault based on the casing vibration acceleration," Measurement, vol. 65, pp. 71-80, 2015. 
[28] G. Chen, "Characteristics analysis of blade-casing rubbing based on casing vibration acceleration," Journal of Mechanical Science and Technology, vol. 29, no. 4, pp. 1513-1526, 2015.

[29] G. Chen, "Simulation of casing vibration resulting from bladecasing rubbing and its verifications," Journal of Sound and Vibration, vol. 361, pp. 190-209, 2016.

[30] N. Wang, C. Liu, D. Jiang, and K. Behdinan, "Casing vibration response prediction of dual-rotor-blade-casing system with blade-casing rubbing," Mechanical Systems and Signal Processing, vol. 118, pp. 61-77, 2019.

[31] A. V. Utkin, G. I. Kanel, S. V. Razorenov et al., "Elastic moduli and dynamic yield strength of metals near the melting temperature," in Proceedings of AIP Conference Proceedings, vol. 429, pp. 443-446, Amherst, MA, USA, 1998.

[32] L. F. Vosteen, "Effect of temperature on dynamic modulus of elasticity of some structural alloys," Technical Report Archive and Image Library, 1958.

[33] S. K. Sinha, "Non-linear dynamic response of a rotating radial timoshenko beam with periodic pulse loading at the free-end," International Journal of Non-Linear Mechanics, vol. 40, no. 1, pp. 113-149, 2005. 


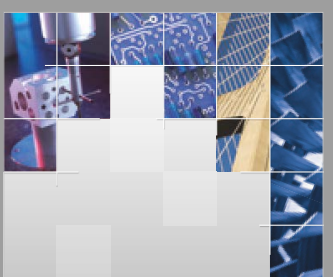

\section{Enfincering}
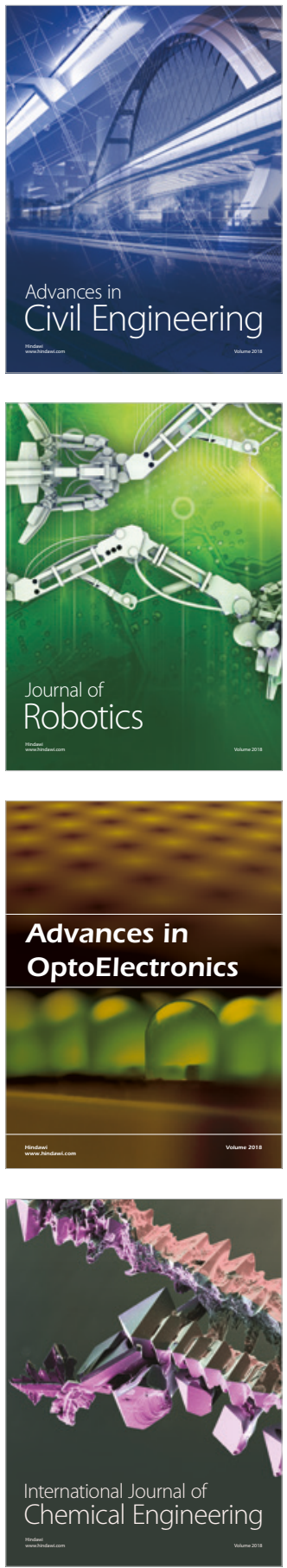

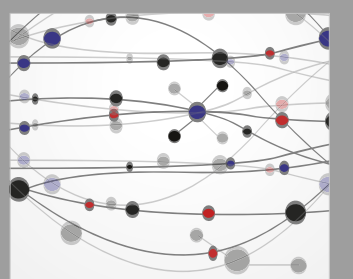

\section{Rotating \\ Machinery}

The Scientific World Journal

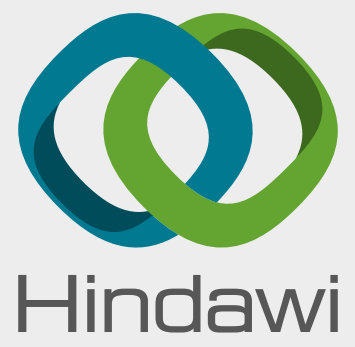

Submit your manuscripts at

www.hindawi.com
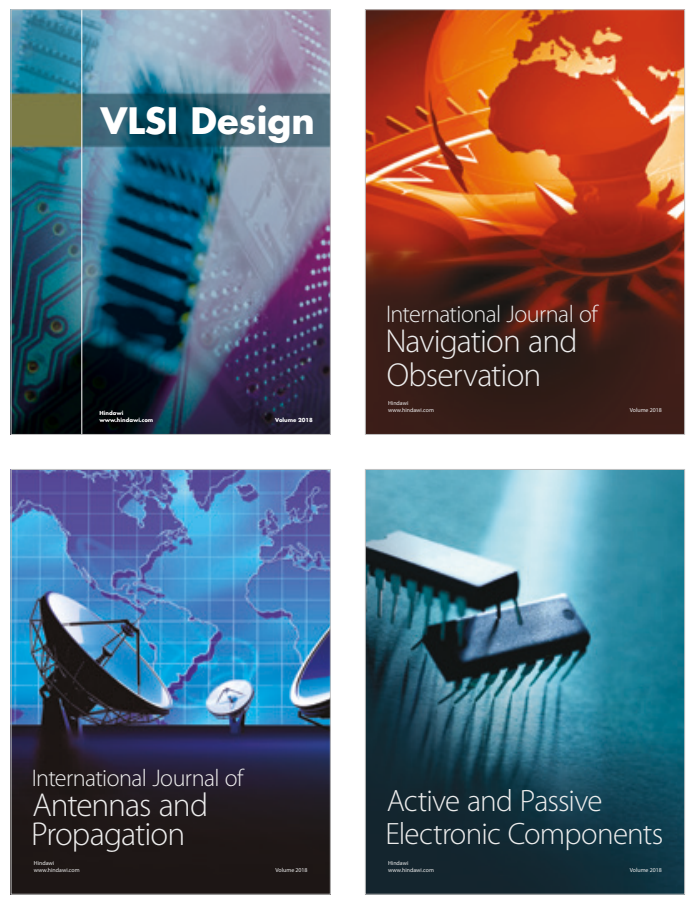
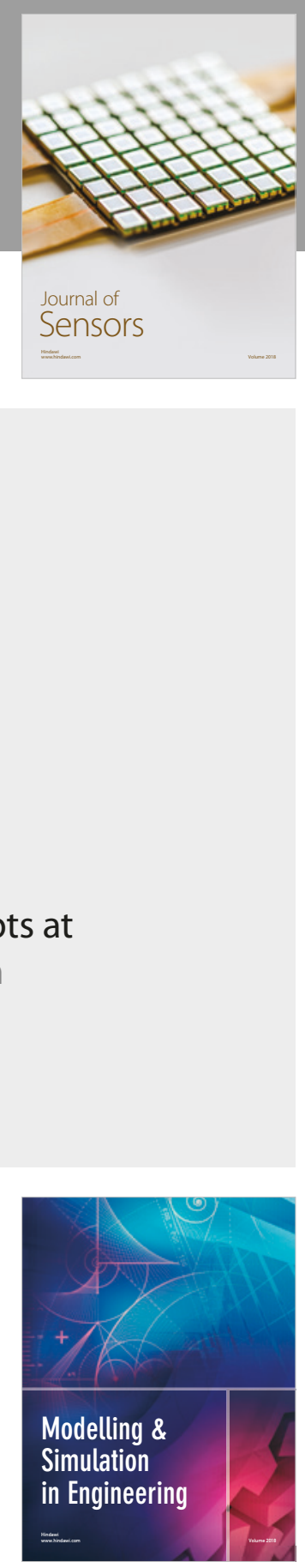

\section{Advances \\ Multimedia}
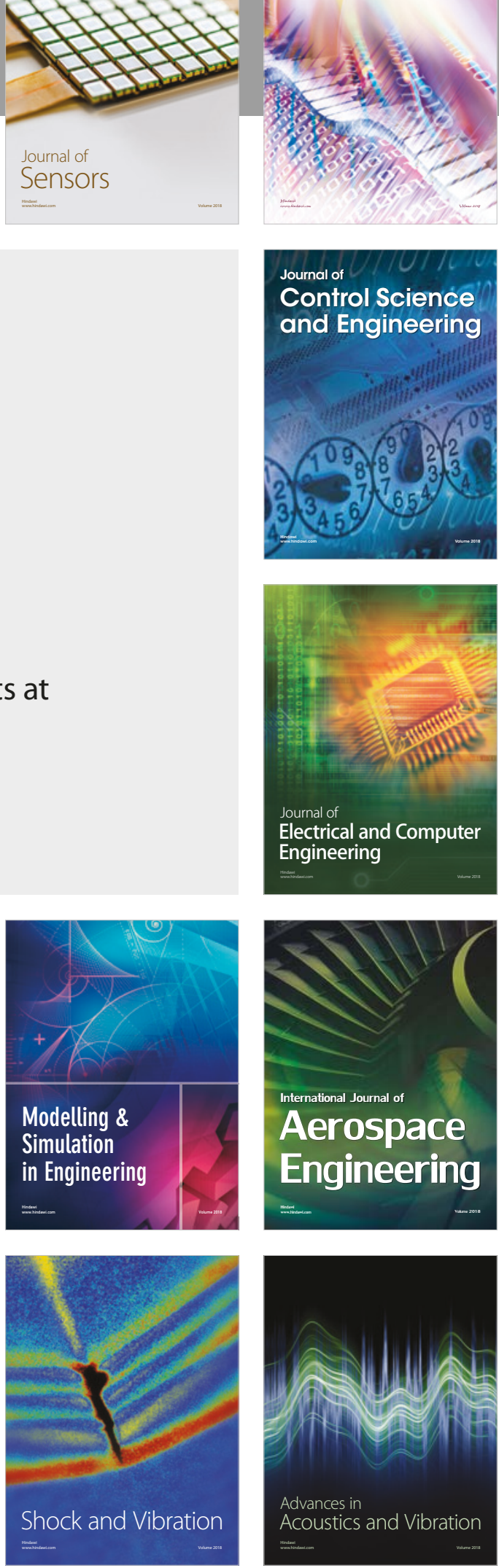